\title{
The role of temperature, mixture fraction, and scalar dissipation rate on transient methane injection and auto-ignition in a jet in hot coflow burner
}

\author{
Christoph M. Arndt ${ }^{\mathrm{a}^{*}}$, Michael J. Papageorge ${ }^{\mathrm{b}}$, Frederik Fuest ${ }^{\mathrm{b}}$, Jeffrey A. Sutton ${ }^{\mathrm{b}}$, Wolfgang Meier ${ }^{\mathrm{a}}$, \\ Manfred Aigner ${ }^{\mathrm{a}}$ \\ ${ }^{a}$ German Aerospace Center (DLR), Institute of Combustion Technology \\ Pfaffenwaldring 38-40, 70569 Stuttgart, Germany \\ ${ }^{\mathrm{b}}$ The Ohio State University, Department of Mechanical and Aerospace Engineering \\ 201 West 19th Avenue, Columbus, OH 43210, USA \\ *Corresponding Author \\ Email: christoph.arndt@dlr.de \\ Phone: +497116862445 \\ Fax: $\quad+497116862578$
}

Full-length paper, To be printed in black / white; all figures to appear in color on the Web

Keywords:

auto-ignition, Rayleigh scattering, high speed planar laser diagnostics, jet in hot coflow, transient jets

\begin{abstract}
The transient injection and subsequent auto-ignition of a methane jet issuing into a laminar coflow of hot exhaust gas from a lean premixed hydrogen air flame was studied using high-speed planar Rayleigh scattering, yielding two-dimensional measurements of mixture fraction, temperature and scalar dissipation rate with high spatio-temporal resolution. The temporal development of the mixing field between the transient fuel jet and the surrounding coflow prior to the occurrence of auto-ignition was examined at a sampling rate of $10 \mathrm{kHz}$. The impact of the transient jet development on numerical modeling of this test case is discussed. It was found that auto-ignition occurred after the jet transitioned from a transient state into the steady state, thus eliminating the need to model the complete transient fuel injection when the primary focus is on the onset of auto-ignition.

Simultaneous high-speed $\mathrm{OH}^{*}$ chemiluminescence from two viewing angles was applied to gain 3Dinformation of the ignition kernel location. This information allowed the selection and analysis of ignition events where the initial kernel formed inside the laser light sheet. Detailed analysis of the dynamics of a single ignition event, as well as statistical analysis of multiple ignition events based on a joint probability density approach, indicated that the ignition kernels occurred at very lean mixture fractions and at locations with low scalar dissipation rates.
\end{abstract}




\section{Introduction}

The mixing and auto-ignition of (cold) fuel in a hot oxidizer stream is of great technical importance in several combustion systems, including internal combustion engines operating under diesel or homogeneous compression charge ignition (HCCI) conditions, gas turbine combustors employing FLOX $^{\circledR}$, MILD or reheat combustion, and scramjet applications. Auto-ignition in lean premixed gas turbine combustion can lead to the establishment of a flame in an undesired region such as the mixing section and therefore lead to combustor damage [1]. Similarly, auto-ignition must be prevented in the mixing duct of reheat combustors, where fuel is injected into the lean (diluted) combustion products of a primary combustion stage [2]; in spark-ignition internal combustion engines to avoid knock; and in flammable material storage. Additionally, auto-ignition can play an important role in the flame stabilization in combustors with high recirculation, such as swirl-stabilized combustors [3] or FLOX ${ }^{\circledR}$ combustors [4]. In MILD combustion [5] and High Temperature Air Condition (HiTAC) [6] the temperature of one or all of the reactants is higher than the auto-ignition temperature of a stoichiometric mixture [5-7] and thus auto-ignition can contribute significantly to the flame stabilization. Finally, it has been noted that in scramjet applications with flameholders auto-ignition plays a significant role in the flame stabilization mechanism due to the transport of hot gases into a lower-speed location.

Due to the complexity of the underlying physical and chemical processes, auto-ignition remains a challenging field of research. While auto-ignition is a transient process, the majority of previous experimental studies in turbulent flows have focused on stably burning lifted jet flames which are stabilized by auto-ignition. Here, continuously-fed fuel jets were studied, either issuing into hot air [8, 9], or into a coflow of hot, vitiated combustion products [10-17]. The latter configuration is termed jet in hot coflow or JHC, and has gained significant research interest in recent years [18].

Cabra et al. $[10,11]$ performed point-wise Raman/Rayleigh/laser-induced fluorescence measurements in nitrogen-diluted hydrogen and in methane jets with vitiated coflow temperatures between $1045 \mathrm{~K}$ and $1350 \mathrm{~K}$. They measured peak temperatures as an indicator for heat release conditioned on the mixture fraction at different axial locations. For the lower axial locations it was found that heat release occurred at mixture fractions much leaner than the stoichiometric mixture fraction, while for the higher axial locations, heat release occurred at values close to the stoichiometric mixture fraction.

Temperature imaging via Rayleigh scattering in JHC configurations has been performed by Medwell et al. [14] and Gordon et al. [15]. Both studies used simultaneous $\mathrm{OH}$ and $\mathrm{CH}_{2} \mathrm{O}$ planar laser-induced fluorescence (PLIF) to gain information about ignition-kernel formation and flame stabilization mechanisms. Medwell et al. [14] found a strong influence of the coflow oxygen content on the peak temperature in the reaction zone. Gordon et al. [15] observed isolated ignition kernels corresponding to a rise of temperature and $\mathrm{CH}_{2} \mathrm{O}$ concentration; however, $\mathrm{OH}$ was not present in all ignition kernels, 
indicating auto-ignition (and not flame propagation) is a primary mechanism behind lifted flame stabilization. With the recent development of high-speed laser measurement and imaging techniques [19-21], new insights into the mechanisms governing auto-ignition has been gained in transient systems [17, 22-31]. In the current work, high-speed laser-based measurements are used to reveal details of the roles of temperature, mixture fraction, and scalar dissipation rate on auto-ignition within a JHC configuration.

One approach to study auto-ignition is with the use of transient jets via pulsed fuel injection. However, to understand auto-ignition in such a transient system, first the behavior of the transient jet has to be studied in detail. The first attempts to derive scaling laws for transient jets (i.e., jet penetration depth) were made by Witze [32]. It was shown that the centerline velocity of an impulsively-started jet reached the steady-state jet value very quickly (after a few milliseconds) and thus it was concluded that transient jets can be treated quasi-steady. The jet penetration was found to scale linearly with time until the jet tip reaches a certain distance from the nozzle exit; afterwards, the jet penetration scales with the square root of time [33]. Soulopoulos et al. [34] performed scalar dissipation rate measurements in a starting jet and found that high values of scalar dissipation rate were concentrated at the jet boundary as well as at random regions in the jet body.

Sadanandan et al. [22] studied the ignition of near-stoichiometric hydrogen/air mixtures by means of hot exhaust gas jets using high-speed Schlieren imaging and planar laser-induced fluorescence of $\mathrm{OH}$. The ignition was observed to occur near the tip of the exhaust gas jet and no ignition was observed at the periphery of the jet, where the strain rate is expected to be high. Fast et al. [23] studied the autoignition of a transient dimethyl ether jet in a high-pressure environment using high-speed shadowgraphy imaging. They observed a two-stage ignition process. Johannessen et al. [31] studied auto-ignition in unsteady hydrogen/nitrogen jets in a hot coflow using high speed Schlieren imaging and microphone probes. It was found that the ignition frequency was dependent on the nitrogen mole fraction in the jet. Oldenhof et al. [17] studied the ignition of impulsively-started natural gas jets issuing into a hot vitiated coflow. Initially, a laminar flow phase was observed, followed by a rapid transition to a turbulent phase after a few milliseconds. No flame reactions were observed in the initial laminar phase. Flame structures were only observed in regions with velocities close to the coflow velocity and it was concluded that transport of coflow fluid into the jet periphery governs the autoignition time.

One difficulty in many of the previous experiments was the accomplishment of well-defined boundary conditions; for example, providing a homogeneous gas distribution within the coflow or knowledge of the temperature of the fuel jet. Other difficulties are out-of-plane effects. When observing an ignition kernel with planar laser measurement techniques, it is of great importance to know whether this ignition kernel formed within the measurement plane or if it formed outside the measurement plane and was convected into the measurement plane by transport processes. Arndt et al. [28, 29] studied the 
auto-ignition of a transient fuel jet issuing into a hot vitiated coflow with well-defined boundary conditions using high-repetition-rate planar laser diagnostics and high-speed imaging.

Chemiluminescence imaging from two viewing angles was used to reconstruct the downstream location of an auto-ignition kernel as well as its position relative to the measurement plane. Recently, Ma et al. [35] used high-speed tomographic chemiluminescence to study the ignition dynamics in a Mach 2 combustor following spark ignition and the subsequent spatio-temporal evolution of ignition kernels.

The aforementioned studies have yielded insight into the statistics of auto-ignition time and location, but no major information has been available concerning the role of turbulence or turbulent mixing. As described in a review paper by Mastorakos [36], direct numerical simulations (DNS) of igniting mixing layers with simplified [37-41] and detailed [42-46] chemistry have shown that auto-ignition occurs away from the stoichiometric mixture fraction at the so-called most-reactive mixture fraction. In the case of cold fuel issuing into an environment of a hot oxidizer, two competing mechanisms determine the mixture fraction at which ignition initially occurs. For very lean mixture fraction conditions, the mixture temperature is high, while the fuel concentration is low. For richer mixtures, the fuel concentration increases, but the mixture temperature decreases. The optimal composition with the shortest ignition delay time is called the most-reactive mixture fraction. However, DNS in turbulent mixing layers has shown that not all locations with the most-reactive mixture fraction ignite at the same time [36]. This finding was supported from previous experimental results [28, 29], where auto-ignition was observed in the form of localized ignition kernels. In DNS, fluctuations of the scalar dissipation rate were found to play a key role in determining the probability of auto-ignition in transient systems; here, ignition occurs first in localized kernels at locations with minimal scalar dissipation rates [42, 44-46], as is found in the cores of vortices [38-40]. Kerkemeier et al. [47] performed 3D direct numerical simulations with detailed chemistry of a hydrogen plume that ignited in a hot, turbulent coflow. In this study ignition occurred in the form of auto-ignition spots at the most reactive mixture fractions and at locations with low scalar dissipation rate, far downstream of the fuel injector. While previous DNS studies have highlighted the importance of the mixture fraction topology and scalar dissipation rate fluctuations in the auto-ignition process, no previous experimental studies have examined the role of the mixture fraction and scalar dissipation rate on auto-ignition.

In order to study effects of turbulence and mixing on auto-ignition experimentally, time-resolved measurements of mixture fraction and temperature fields with sufficient spatial resolution prior to the onset of auto-ignition are necessary. Due to the limited pulse energy of continuously-operating highrepetition-rate laser systems, only a subset of well-established laser-based imaging techniques have been applied at high acquisition-rates. In JHC configurations, only PIV and OH PLIF in combination with flame emission and Schlieren imaging have been employed at $\mathrm{kHz}$ rates. With the development and continued improvement of pulse-burst laser systems [48], methods requiring high laser pulse 
energies, such as planar Rayleigh scattering for mixture fraction or temperature imaging [49-52], or major species concentration via Raman scattering [53] have become possible at multi-kHz acquisition rates.

In the current study, the High-Energy Pulse-Burst Laser System (HEPBLS) at Ohio State [50, 54] was employed to study the mixing process during transient injection of a methane fuel jet in the DLR Jet in Hot Coflow Burner (DLR JHC) using planar Rayleigh scattering with high temporal resolution. Quantitative measurements of mixture fraction, and scalar dissipation rate prior to auto-ignition and temperature throughout auto-ignition events were deduced which can be used as validation data for numerical models. The temperature boundary conditions of the DLR JHC are described in detail, as they are important for numerical modeling of this experiment. A detailed characterization of the transient fuel injection into a hot, vitiated coflow is performed, where the focus is on the temporal evolution of the mixing field and the transition from a transient state to the steady state. Furthermore, the subsequent auto-ignition and the influence of mixture fraction and scalar dissipation rate on autoignition sites are studied using a joint probability density function approach. 


\section{Experiment and diagnostics}

The laser system $[30,50,54]$ and combustor $[28,29]$ have been described previously, so only the key parameters are presented here.

\subsection{DLR Jet in Hot Coflow Burner and operating conditions}

Figure 1 shows a schematic of the DLR Jet in Hot Coflow Burner (DLR JHC). The coflow consists of the hot, oxygen-containing exhaust gas from a lean premixed hydrogen/air flat flame stabilized on a quadratic, $75 \times 75 \mathrm{~mm}^{2}$, water-cooled sintered bronze matrix. Two quartz windows were used to reduce disturbance of the exhaust gas flow by ambient air. In contrast to previous studies [28, 29], the laser entrance and exit side windows were removed due to the high laser pulse energies applied in this work. However, no influence of entrained room air was found at the studied measurement locations, as will be discussed below. The nozzle was a stainless steel tube (inner diameter $D=1.5 \mathrm{~mm}$ ), where the tip of the nozzle was $8 \mathrm{~mm}$ above the matrix. The origin of the coordinate system $(x, y, z=0)$ corresponds to the center of the tip of the fuel nozzle.

Methane was injected in a pulsed manner into the hot coflow using a 2/2 way solenoid valve (Staiger VA204-5), located approximately $250 \mathrm{~mm}$ (or $165 \mathrm{D}$ ) below the nozzle exit to ensure fully developed pipe flow. In contrast to previous studies [28, 29], a valve with a larger orifice $(1.5 \mathrm{~mm})$ was used to minimize the stagnation pressure in front of the valve between pulses. For the present configuration, the stagnation pressure was 0.8 bar.

The operating conditions are summarized in Table 1 for the jet and vitiated coflow. For the coflow operating condition, the adiabatic equilibrium temperature $\left(T_{a d}\right)$, measured coflow temperature $\left(T_{\text {coflow }}\right)$, and species mole fractions for the coflow gases are shown. The flow rates were controlled with Brooks MFC5850 mass flow controllers and monitored with coriolis flow meters (Siemens Sietrans Mass 2100 ) with a maximal measurement uncertainty of $1.2 \%$ per manufacturer's specifications. Previous measurements in a similar configuration have shown that the exhaust gas temperature stays very close to $T_{a d}$ if heat loss to the matrix is minimized [55]. To meet this criterion the velocities of the unreacted gas were chosen to exceed $0.7 \mathrm{~m} / \mathrm{s}$ which corresponds to a velocity of $4.1 \mathrm{~m} / \mathrm{s}$ for the high-temperature product gases. Rayleigh scattering measurements and data processing as described in [30] were used to determine the coflow temperature, which was $1490 \mathrm{~K}$, or approximately $4.5 \%$ below $T_{a d}$. A coriolis meter placed in line with the $\mathrm{CH}_{4}$-injection system was used to calculate the bulk flow velocity and jet exit Reynolds number. The steady-state exit velocity was $178 \mathrm{~m} / \mathrm{s}$ and the resultant jet Reynolds number was 15,400 . 
The fuel injection duration can be varied from less than $2 \mathrm{~ms}$ to continuous operation; however, no influence of the valve opening time on the auto-ignition was found for valve opening times greater than $3 \mathrm{~ms}$ [27]. In the current study, the solenoid valve opening time was $55 \mathrm{~ms}$, which is more than sufficient for auto-ignition ( $\sim 2 \mathrm{~ms}$ ) and the establishment of a stably burning flame ( $<4 \mathrm{~ms}$ ) [27-29], but short enough to minimize any influence of burner heating for subsequent measurement bursts.

Before the measurements, the matrix burner was run for at least ten minutes to achieve thermal equilibrium. Subsequently, a trigger started the laser burst, the recording of the cameras, and the opening of the solenoid valve to start the pulsed jet. This procedure was repeated 30 times at a rate of $0.05 \mathrm{~Hz}$. The time in between subsequent transient fuel injection/laser bursts/auto-ignition events was 20 seconds which corresponds to approximately 330 times the coflow advection time ( $\mathrm{v}_{\text {coflow }} /$ combustion chamber height). This low duty cycle enabled the flow field to regain a stationary state without the jet in between runs. After 30 recording cycles the images were downloaded from the cameras to a data acquisition computer and the sequence was repeated. This process was repeated ten times, resulting in 300 individual transient injection/auto-ignition cases.

\subsection{The High-Energy Pulse-Burst Laser System (HEPBLS) and Rayleigh imaging}

Simultaneous mixture fraction and temperature measurements were derived from high-speed $(10 \mathrm{kHz})$ planar Rayleigh scattering imaging. In order to generate the high laser pulse energies necessary for Rayleigh scattering measurements with high signal-to-noise (SNR), the High-Energy Pulse-Burst Laser System (HEPBLS) at Ohio State was used [50, 54]. A continuously operating pulsed Nd:YVO laser was amplified in six flashlamp-pumped Nd:YAG amplifier stages. The first three amplifier stages were operated in a double-pass configuration and the final three amplifier stages were operated in single-pass configuration. Following the last amplification stage, the output beam was frequency doubled to $532 \mathrm{~nm}$. Pulse energies $>1 \mathrm{~J}$ at $532 \mathrm{~nm}$ and burst lengths of 230 pulses were achieved at a pulse repetition rate of $10 \mathrm{kHz}$. Since the laser beam has a diameter of approximately $15 \mathrm{~mm}$ in the test section, no beam expansion was employed and the laser-sheet was formed by focusing the beam into the test section with a single, plano-convex cylindrical lens $(\mathrm{f}=750 \mathrm{~mm})$, resulting in a lasersheet thickness in the test section of $<300 \mu \mathrm{m}$.

Figure 2 shows the optical and imaging setup for the current measurements. A pair of Phantom v711 high-speed CMOS cameras was used to image the Rayleigh-scattering signal from both the DLR JHC and from an additional laminar air flow adjacent to the test section for laser-sheet intensity profile and pulse-to-pulse laser energy corrections. Rayleigh-scattering from the test section was collected using a combination of a 100-mm-diameter, $\mathrm{f}=240 \mathrm{~mm}$ focal length achromat lens and a Nikon, $85 \mathrm{~mm}, \mathrm{f} / 1.4$ camera lens to maximize light collection for the desired in-plane spatial resolution. The laser-sheet 
correction camera was outfitted with a Nikon $85 \mathrm{~mm} \mathrm{f} / 1.4$ camera lens. For the current measurements, the Rayleigh camera had an active array of $400 \times 912$ pixels, the sheet-correction camera had an active array of 512 x 208 pixels, and the exposure time was $1 \mu$ s for both cameras. More details of the highspeed Rayleigh scattering imaging system can be found in $[30,50]$.

\subsection{Chemiluminescence imaging}

Imaging of $\mathrm{OH}^{*}$ chemiluminescence (CL) was performed using two intensified high-speed CMOS cameras (Photron SA5 with LaVision HS-IRO), equipped with high-throughput UV lenses (Cerco $100 \mathrm{~mm}, \mathrm{f} / 2.8)$ and high-transmission bandpass filters (> $80 \%$ transmission at $310 \mathrm{~nm}$ ). Both cameras were operated at an imaging rate of $10 \mathrm{kHz}$. The active array for both cameras was $896 \mathrm{x} 848$ pixels. One camera, mounted to the left of the Rayleigh cameras as shown in Fig. 2, was used to gain information on time and downstream location of the initial auto-ignition event. The second camera was looking along the laser-sheet and was used to determine the position of the ignition kernels relative to the laser-sheet. Only ignition kernels that formed inside the laser-sheet were included in the data analysis. With an exposure time of $35 \mu$ s for each CL camera, and a velocities ranging between $4 \mathrm{~m} / \mathrm{s}$ (coflow velocity) and $180 \mathrm{~m} / \mathrm{s}$ (jet exit velocity), a maximum image slip of $6.3 \mathrm{~mm}$ is expected in the chemiluminescence imaging. However, since auto-ignition occurs at the outmost periphery of the jet, where the velocities are dominated by the coflow velocity, this effect was found to be approximately $0.1 \mathrm{~mm} /$ frame and thus negligible.

\subsection{Data reduction and analysis}

The post-processing of the $\mathrm{OH}^{*} \mathrm{CL}$ images is similar as described in $[28,29]$ and will not be discussed here in detail. First, whitefield, darkframe, and background correction were performed. For reducing the background noise from the image intensifiers, for example due to single photon events, which lead to high count levels in small areas, a minimum size of 100 pixel or $2 \mathrm{~mm}^{2}$ for valid ignition kernels was defined, all other events were regarded as noise.

Details of the Rayleigh scattering imaging post-processing can be found in [30]. First, the raw images were corrected to account for sensor offset using a darkframe correction. Non-uniformity in the sensor response was corrected by normalizing each Rayleigh-scattering image with an averaged image from ambient air, as described in [50]. Finally, the sheet correction and signal cameras were mapped onto a common image size and the spanwise laser-sheet intensity correction was performed using an average of a 25 pixel wide column from the sheet-correction camera. Calculating the mixture fraction and temperature fields from the measured Rayleigh-scattering imaging was a multi-step process. First the 
NASA Chemical Equilibrium with Applications (CEA) code [56] was used in conjunction with measured Rayleigh-scattering signals in the coflow to determine the oxidizer stream temperature and composition. With the assumption that the equivalence ratio of the coflow reactants is known, a (nonadiabatic) temperature (and the associated equilibrium composition) was iterated upon until it converged with that expected from the measured signal ratio of the hot coflow to cold air.

After establishing the oxidizer temperature, a multi-step procedure is used to determine the local fuel mole fraction $\left(X_{f u e l}\right)$ and temperature $(T)$ as a function of space and time. For the two-stream mixing problem of cold fuel and the hot oxidizer, the ratio $(S)$ of the local Rayleigh-scattering signal to the Rayleigh-scattering signal from cold air at $T_{\text {air }}=300 \mathrm{~K}$, is written as

$\mathrm{S}=\frac{\mathrm{X}_{\mathrm{fuel}} \cdot \sigma_{\mathrm{fuel}}+\left(1-\mathrm{X}_{\mathrm{fuel}}\right) \cdot \sigma_{\mathrm{ox}}}{\mathrm{T} / \mathrm{T}_{\mathrm{air}} \cdot \sigma_{\mathrm{air}}},(1)$

where $\sigma_{\text {air }}, \sigma_{\text {ox }}$, and $\sigma_{\text {fuel }}$ are the Rayleigh scattering cross-sections of air, hot oxidizer stream, and fuel respectively, and $T$ is the local temperature. The ratio $T / T_{\text {air }}$ represents the ratio of the number densities of the reference air stream and the measurement volume, as derived from the ideal gas law. It is noted that Eq. (1) only is valid prior to combustion, as described in [30]. After the occurrence of ignition, the mixture fraction and scalar dissipation rate cannot be determined from the Rayleigh scattering signal. The relationship between $X_{f u e l}$ and $T$ is established by considering enthalpy conservation during mixing of the two streams. Using an enthalpy balance between fuel and oxidizer streams along with Eq. (1), a library of signal ratios between Rayleigh-scattering signal (corresponding to $X_{\text {fuel }}$ and $T$ ) and cold air is calculated. Using the pre-tabulated library, the temperature and mole fraction fields are directly determined from the measured signal ratio. Once the local fuel mole fraction is determined, the local mixture fraction $(\xi)$ is calculated as

$\xi=\mathrm{Y}_{\text {fuel }}=\frac{\mathrm{X}_{\text {fuel }} \cdot \mathrm{W}_{\text {fuel }}}{\mathrm{X}_{\text {fuel }} \cdot \mathrm{W}_{\text {fuel }}+\left(1-\mathrm{X}_{\text {fuel }}\right) \cdot \mathrm{W}_{\mathrm{ox}}},(2)$

where $Y_{\text {fuel }}$ and $W_{\text {fuel }}$ are the mass fraction and molecular weight of the fuel, respectively, and $W_{o x}$ is the molecular weight of the hot oxidizer stream. Eq. (2) also is only valid prior to the onset of autoignition, as will be discussed below. Finally, the data is filtered by a $3 \times 3$ pixel median filter to increase the signal-to-noise ratio; however, this spatial filtering still leads to an in-plane spatial resolution better than the out-of-plane resolution as defined by the laser-sheet thickness.

Possible sources for measurement uncertainty are the quantities in Eq. (1) and potential pre-ignition chemistry. The Rayleigh scattering cross sections of methane, air, and of the different species in the coflow are well known from the literature, and thus no impact on the measurement uncertainty is expected. However, the mixture-averaged Rayleigh scattering cross section of the coflow depends on the equivalence ratio and thus on the measurement uncertainty of the mass flow meters. They were $1.2 \%$ for the air mass flow and $0.5 \%$ for the hydrogen mass flow, resulting in a maximal uncertainty 
of the coflow equivalence ratio of $1.5 \%$. Hence, the mixture averaged Rayleigh scattering cross section of the coflow has an uncertainty of approximately $1 \%$. Also, the temperature of the calibration coflow was not monitored constantly, resulting in an additional measurement uncertainty of the calibration flow temperature of $5 \mathrm{~K}$ or $2 \%$. Furthermore, the measurement uncertainty of the local temperature $T$ is governed by the signal-to-noise ratio, which is on the order of $1 \%$ (see section 3.1). Due to the high temperatures of the coflow one potential concern is the pre-ignition thermal dissociation of fuel and subsequent oxidation, and its implication on the mixture-averaged Rayleigh scattering cross section and, thus, the measurement precision and uncertainty. The most probable locations of chemical reaction occur near the jet periphery where the gas temperatures are hot. In our previous work [30] kinetic calculations were performed, using a series of plug flow reactor simulations and the boundary conditions of the experiment. The modeling results showed that the decomposition or oxidation of $\mathrm{CH}_{4}$ was negligible for all expected residence times. As discussed in [30], the methodology developed for determining mixture fraction and temperature simultaneously only is strictly valid prior to ignition. However, it was shown that a reasonable estimate of the gas temperature was possible following ignition. In regions of reacted gas, the molecular composition and the effective Rayleigh cross sections are different from those of the non-reacted gas. In order to assess this influence on the uncertainty of the temperature measurements, an estimation using a one-step reaction mechanism was performed and the resulting temperature error was found to be less than $4 \%$ [30].

One of the goals of the current research is to investigate the role of mixture fraction gradients (as a marker for the scalar dissipation rate) prior to the auto-ignition process. To accurately resolve mixture fraction gradients, both high SNR and spatial resolution are required. Based on measurements in a series of bar patterns with varying spatial frequencies, the in-plane spatial resolution allows mixture fraction gradients as high as $4 \mathrm{~mm}^{-1}$ to be measured accurately. The effect of the out-of-plane spatial resolution on the resolvable gradients has not been determined. Measurement noise limits the minimum spatial gradients that can be measured accurately. Based on the results presented below, mixture fraction gradients as small as $0.2 \mathrm{~mm}^{-1}$ can be measured in the hot coflow region $(\xi=0)$; for $\xi$ $>0$, smaller mixture fraction gradients are resolvable due to higher SNR. 


\section{Results and discussion}

\subsection{Boundary conditions and reproducibility}

For numerical modeling of auto-ignition, precise knowledge of the temperature boundary conditions is crucial, as the ignition delay time depends exponentially on the mixture temperature. Small temperature fluctuations can produce a significant change in auto-ignition time and location, or determine whether a mixture can auto-ignite for certain boundary conditions [57]. The temperature profile of the coflow of the DLR JHC (without fuel jet) is shown in Fig. 3 for different heights above the burner between $\mathrm{z}=20 \mathrm{~mm}$ and $\mathrm{z}=50 \mathrm{~mm}$. Each temperature profile is temporally averaged over 100 single shots without spatial averaging. The dashed line represents the calculated adiabatic flame temperature for the coflow operating condition. Near the jet centerline at $\mathrm{x}=0 \mathrm{~mm}$, a decrease in temperature is visible, which stems from the fuel nozzle. The fuel nozzle is in contact with the watercooled sinter-matrix and thus is much colder than the gas in the coflow. This has a cooling effect on the adjacent fluid. However, this temperature decrease is quite small (on the order of $2.5 \%$ at $\mathrm{z}=$ $40 \mathrm{~mm}$ ), and most auto-ignition events observed occurred at radial locations that are not influenced by this region. Furthermore, the volume influenced by the cooling effect of the fuel nozzle is quite small, and is rapidly mixed with the surrounding coflow fluid when the transient jet is operated. Thus, in the reacting case, no influence of the cooled nozzle on the temperature distribution is expected. Further out in the radial direction a slight decrease in temperature on the order of $1-2 \%$ towards the edges of the burner (increasing $|\mathrm{x}|$ ) is visible. It is noted that ignition kernels are not influenced by the temperature decrease towards the periphery of the coflow either, since the ignition kernels are only observed at $|\mathrm{x}|<10 \mathrm{~mm}$. Figure 3 also shows that there only is a minimal influence of the axial position on the measured temperature profiles. The decreased temperature in the coflow at $\mathrm{z}=50 \mathrm{~mm}$ most likely stems from fluctuations of mass flows within the accuracy limits of the flow controllers and thus the coflow equivalence ratio. Additionally, the temperature profiles show that no entrainment of ambient air occurs at the locations relevant for auto-ignition. Effects of entrainment are only visible at $\mathrm{z} \geq 50 \mathrm{~mm}$ and $|\mathrm{x}| \geq 20 \mathrm{~mm}$.

Probability density functions (PDFs) of temperature were computed at several positions. Figure 4a shows the PDFs for different axial locations at a radial position of $x=10 \mathrm{~mm}$, while Fig. $4 \mathrm{~b}$ shows the temperature PDFs for different radial locations at an axial position of $z=40 \mathrm{~mm}$. The PDFs were calculated from 250 single shot temperature measurements; the temperature from each single shot measurement was spatially averaged over an area of $5 \times 5 \mathrm{~mm}^{2}$ (8200 pixels) in order to eliminate the influence of noise on the temperature PDFs. With increasing axial position, a shift towards lower temperatures is observed. The mean temperature at $\mathrm{z}=20 \mathrm{~mm}$ is $1497.3 \mathrm{~K}$ with a standard deviation of $3.20 \mathrm{~K}$, while at $\mathrm{z}=40 \mathrm{~mm}$, the mean temperature is $1493.0 \mathrm{~K}$ with a standard deviation of $6.25 \mathrm{~K}$. However, this corresponds to a decrease in temperature of only $0.2 \%$ over an axial distance of $20 \mathrm{~mm}$. The very small standard deviation of the temperature shows the reliability of the boundary conditions; 
in similar studies in other facilities, higher standard deviations of the coflow temperature have been observed [58]. With respect to a change in radial location, the temperature decreases from $1493 \mathrm{~K}$ at $\mathrm{x}$ $=10 \mathrm{~mm}$ to $1483 \mathrm{~K}$ at $\mathrm{x}=20 \mathrm{~mm}$, which is equivalent to a decrease of $0.7 \%$.

The average temperature for a single representative Rayleigh-scattering image within the coflow (between $36 \mathrm{~mm}<\mathrm{z}<44 \mathrm{~mm}$ and $12 \mathrm{~mm}<\mathrm{x}<20 \mathrm{~mm}$ ) is $1490 \mathrm{~K}$, with a standard deviation of $1 \%$ on a single pixel basis. The precision of the temperature averaged over the region $36 \mathrm{~mm}<\mathrm{z}<44 \mathrm{~mm}$ and $12 \mathrm{~mm}<\mathrm{x}<20 \mathrm{~mm}$ is better than $0.3 \%$ over one burst of images (i.e., 100 sequential images at $10 \mathrm{kHz}$ ). The adiabatic flame temperature of the lean premixed $\mathrm{H}_{2} /$ air flame at $\varphi=0.465$ is $1561 \mathrm{~K}$ which is $71 \mathrm{~K}$ or $4.5 \%$ higher than the measured coflow temperature. This can be explained by heat losses to the matrix and heat losses due to radiation. Uncertainties in the coflow flow rates can result in a temperature uncertainty of $\pm 2 \%$ or $\pm 30 \mathrm{~K}$ and measurement uncertainties of the Rayleigh system are as well estimated to be $\pm 2 \%$. The standard deviation of the average temperature between the 300 measured runs is $0.8 \%$ and represents the long-time temperature stability.

\subsection{Mixture fraction, temperature and scalar dissipation rate fields during transient jet injection}

In order to understand the dynamics of the mixing process of pulsed fuel injection into a hot oxidizer, both temperature and mixture fraction were derived from the time-resolved Rayleigh scattering signal at several axial locations using the method outlined above. Figure 5 shows a mosaic of example mixture fraction fields for individual injection events between $\mathrm{z}=15 \mathrm{~mm}$ and $\mathrm{z}=55 \mathrm{~mm}$. The blue regions of mixture fractions $0.025>\xi>0$, which can be seen around the jet centerline at all axial locations before the jet passes the measurement region, are artefacts from the data analysis process. As shown in Fig. 3, a temperature decrease is observed around the jet centerline due to a cooling effect of the fuel nozzle. Since the Rayleigh signal is calibrated in the coflow-region (away from the jet centerline), this temperature decrease corresponds to an increased Rayleigh scattering signal and is thus interpreted as a small but finite increase in mixture fraction by the data processing algorithm. However, this effect is exaggerated by the logarithmic color map, and only corresponds to mixture fraction fluctuations (standard deviation) of $\xi_{S D}=0.005$. At $t=0.4 \mathrm{~ms}$ and $\mathrm{z}=18 \mathrm{~mm}$ the jet can first be seen in the field of view with the jet tip being at $\mathrm{z} \approx 20 \mathrm{~mm}$. At the jet tip, the jet core has a slightly higher mixture fraction than the outer wings, which is due to a remaining influence of the head vortex of an impulsively started jet [59]. This effect also is observed in the next frame at $t=0.5 \mathrm{~ms}$. Directly below the jet tip, a region with a high level of mixing within the jet core is observed. Further upstream, the jet core remains at a nearly constant mixture fraction $(\xi>0.5)$. This intact jet core is observed up to an axial location of $\mathrm{z}=26 \mathrm{~mm}$ and remains similar during the complete jet injection phase, as seen from the last image frame at $t=2.2 \mathrm{~ms}$, at the onset of auto-ignition. 
The leading edge of the jet has a strong mixture fraction gradient, but the region directly inside of the tip region appears relatively homogeneously mixed. Upstream of the leading edge region, the mixture fraction field has an appearance similar to that of a jet under steady-state operation. Based on previous DNS studies [36, 38, 45] and our previous work [30], auto-ignition is expected within regions of low scalar dissipation (i.e. low mixture fraction gradients) at the jet periphery, where the mixture faction is low and the temperature is high. Due to the high-temperature coflow and the cold fuel jet, the mixture temperature increases with decreasing mixture fraction. Since the ignition delay time is exponentially proportional to the temperature, ignition delay times are shortest for ultra-lean mixtures under the present conditions [29].

Figure 6 shows a mosaic of the temperature field for the same injection events as displayed in Fig. 5. The highest mixture temperatures are reached at the jet periphery, as expected from the mixture fraction fields in Fig. 5. However, at the jet core, high mixture temperatures exceeding $900 \mathrm{~K}$ also can be observed. Throughout the image series (Figs. 5 and 6), strong mixture fraction gradients are present at the jet tip. Thus, also strong temperature gradients, where mixture temperatures close to the coflow temperature can be observed, exist in this region. Due to the high temperatures of the jet core at this axial position, the influence of thermal fuel decomposition was considered in a previous study [30]; however; the influence of elevated temperatures was found negligible for the temperature and residence time range of interest as discussed above. At $t=2.2 \mathrm{~ms}$ and $\mathrm{z}=37 \mathrm{~mm}$, an ignition kernel ( $T$ $>1700 \mathrm{~K}$ ) can be observed at the right periphery of the jet. This ignition event will be discussed in detail in section 3.3.

Figure 7 shows the corresponding mosaic of the square of the two-dimensional gradient of the mixture fraction, which acts as a surrogate of the scalar dissipation rate, for the same injection event that was displayed in Figs. 5 and 6. The square of the mixture fraction gradient $(\nabla \xi)^{2}$ is proportional to the scalar dissipation rate $\chi$ since $\chi=2 \cdot \mathrm{D} \cdot(\nabla \xi)^{2}$, where $D$ is the molecular diffusivity. The temperature dependence of the diffusion coefficient $D$ is neglected here, since $(\nabla \xi)^{2}$ is only used as a qualitative marker of the scalar dissipation rate. As expected from the mixture fraction fields in Fig. 5, high scalar dissipation rates are observed at the tip of the impulsively-started jet shown in Fig. 7 (see the corresponding large mixture fraction gradients in Fig. 5). At the lower axial locations (around $\mathrm{z}=$ $20 \mathrm{~mm}$ ), high scalar dissipation rates and fine-scale structures are observed as well, with an increasing number of structures in the jet center and at the jet periphery. At the higher axial locations (around $\mathrm{z}=$ $30 \mathrm{~mm}$ and $\mathrm{z}=40 \mathrm{~mm}$ ), high scalar dissipation rates are observed, but only after the jet tip has passed the measurement regions. However, it is noted that for a fixed axial position, the number (and intensity) of the scalar dissipation rate layers decreases with further increases in time. As one example, at $t=2.2 \mathrm{~ms}$ (the time at which auto-ignition occurs in the displayed image series, as will be discussed below), the scalar dissipation rates at the jet centerline and at the jet periphery have decreased significantly. This is especially true for axial positions above $\mathrm{z}=35 \mathrm{~mm}$, where regions with very low 
scalar dissipation rates are observed at the jet periphery. As will be shown below, these regions are the preferable locations where the initial auto-ignition kernels will form. Also, it is noted that in lean mixtures at the jet periphery, the velocity is dominated by the hot coflow velocity and thus exhibits a lower turbulence level as compared to regions dominated by the jet flow. Furthermore, the residence time of an igniting mixture pocket can be expected to be larger in this region. Such regions can be observed at $\mathrm{z}>34 \mathrm{~mm}$ at $t=2.2 \mathrm{~ms}$. A transition from an initial laminar phase to a turbulent phase, as observed by Oldenhof et al. [17] in a similar configuration at lower jet Reynolds numbers was not observed in the current experiment. The closed symbols represent the average downstream location of the $\xi=0.1$ iso-line, which is approximately three times the stoichiometric mixture fraction $\xi_{\text {stoich }}=$ 0.0297. The exact time at which the jet exits the fuel nozzle could not be measured, since measurements below $\mathrm{z}=10 \mathrm{~mm}$ were not performed due to a risk of camera damage from reflections of the low-intensity wings of the laser-sheet off the fuel nozzle. However, the jet-exit time can be estimated with sufficient accuracy. In the near field, jet penetration is directly proportional to the time $t[33]$ and the jet penetration can be extrapolated by a linear fit to the first five measured data points, equal to $\mathrm{z}<30 \mathrm{~mm}$ (blue line in Fig. 8). The extrapolation yields the time at which the jet exited the fuel nozzle to be $t=0.05 \mathrm{~ms}$ and a jet tip velocity of approximately $57 \mathrm{~m} / \mathrm{s}$. Here, $t=0$ was defined as the (rounded) time at which the jet exited the nozzle. The slope of the jet tip position and thus the jet tip velocity stays nearly constant up to $t=0.8 \mathrm{~ms}$ or $\mathrm{z}=40 \mathrm{~mm}$, confirming that the jet penetration scales proportional to $t$ in the near field. The standard deviation of the jet tip position until $t=1.0 \mathrm{~ms}$ is less than $1 \mathrm{~mm}$. At z $>40 \mathrm{~mm}$, the slope of the jet penetration changes, and the standard deviation of the jet tip position becomes larger (up to $1.2 \mathrm{~mm}$ at $\mathrm{z}=50 \mathrm{~mm}$ ). Here, the transient jet is expected to become self-similar and the jet tip penetration will follow a slope $\propto t^{1 / 2}$ (red line in Fig. 8) [59]. It is concluded that the jet injection is reproducible and the jet development is similar for all injection events. However, the exact shapes of the mixing and temperature fields still are subject to turbulent fluctuations and will vary from injection to injection. Other instabilities in the system that could be caused by the transient jet were not observed.

To investigate the transition from the transient fuel injection to steady state jet behavior, statistics of the mixture fraction field during the transient fuel injection have been computed. Figure 9 shows the temporal evolution of the mean mixture fraction $\langle\xi\rangle$ for different axial positions. Here, $\langle\xi\rangle$ is defined as the radially averaged mixture fraction at a given axial location. Values of $\xi<\xi_{\text {stoich }}$, which is approximately twice the resolution limit of the measurement, were not included in this evaluation in order to avoid influences of noise and to include only regions in the analysis which are well within the fuel jet. The dashed line represents the evolution of $\langle\xi\rangle$ for one individual injection event at each axial location and the solid line represents the average of 50 individual injection events at each axial location. After the jet tip has passed a given axial position (rise in mixture fraction), the radially averaged mixture fraction reaches its steady-state mean value after fractions of a millisecond. This trend is observed for all axial locations shown in Fig. 9. Thus, the jet is expected to reach steady-state 
behavior in less than $1 \mathrm{~ms}$ after the jet tip has passed the measurement region. To further confirm this trend, Fig. 10 shows the temporal evolution of the mixture fraction profile at $\mathrm{z}=40 \mathrm{~mm}$. Here, the average mixture fraction profile for 50 individual fuel injection events is shown for various times following fuel injection. At $t=1.0 \mathrm{~ms}$, the average profile indicates that the jet tip is passing the measurement region, which is qualitatively confirmed by the image sequences shown in Fig. 6 . By $t=$ $1.5 \mathrm{~ms}$, a steady-state mixture fraction profile is reached, as is confirmed by the comparison to the mixture fraction profile at $t=2.0 \mathrm{~ms}$. Since auto-ignition occurs around $t=2.4 \mathrm{~ms}$ (see below) for the current operating condition, the fuel jet is operating under steady-state behavior before the onset of ignition. This finding is important for numerical modeling, since auto-ignition in this configuration potentially can be modeled with a steady-state fuel jet with the activation of ignition chemistry at a pre-determined induction time in contrast to simulating the full transient fuel injection. However, more work is needed to see if this finding is applicable over a broad range of operating conditions. Similar observations concerning the potential for treating the jet as quasi steady-state for modeling purposes were made by Oldenhof et al. [17], where auto-ignition kernels occurred well after the establishment of a steady state turbulent jet flow. However, it should be noted that the observed ignition delay times of Oldenhof et al. [17] were much longer than those in the present study $(9 \mathrm{~ms}$ and $14 \mathrm{~ms}$ vs. $2.4 \mathrm{~ms}$ in the current experiment). This might stem from the higher Reynolds number jet and lower temperature fluctuations in the DLR JHC, or from the positive temperature gradient of the coflow observed by Oldenhof et al. [17]. More work is needed to understand the influence of the ratio of the ignition delay time to the time to reach steady-state mixing profiles in terms of auto-ignition modeling.

\subsection{Mixture fraction, temperature, and scalar dissipation evolution during auto-ignition}

Figure 11 shows a typical mixture fraction field sequence during auto-ignition. The corresponding temperature fields for the same ignition event are shown in Fig. 12. For both Figs. 11 and 12, the fieldof-views are centered at an axial position of $z=40 \mathrm{~mm}$. Shown on the images are iso-contours of the stoichiometric mixture fraction, $\xi_{\text {stoich }}=0.0297$ (red/black), and iso-contours of a temperature $T=$ $1560 \mathrm{~K}$ (white). The temperature iso-contour was chosen to be sufficiently above the coflow temperature $\left(T_{\text {coflow }}=1490 \mathrm{~K}\right)$ to avoid noise issues while being low enough to visualize an ignition kernel early in its development phase. Other regions of increased temperature that can be observed in Fig. 12 are below $T=1560 \mathrm{~K}$ and thus considered as noise. Only the region right of the jet centerline is shown. The image series starts at $t=2.0 \mathrm{~ms}$ or approximately $1.2 \mathrm{~ms}$ after the jet tip has passed the measurement region. Large regions of very lean mixtures $(\xi<0.1)$ are observed at the jet periphery at this axial location. The maximum mixture fraction at the jet centerline is approximately $\xi=0.37$ and indicates significant mixing even on the jet centerline. Consequently, the temperature on the jet centerline has increased from $300 \mathrm{~K}$ at the nozzle exit to values $T \geq 1000 \mathrm{~K}$ due to the mixing of the cold fuel and hot oxidizer. The interface between the jet and coflow, as represented by the $\xi_{\text {stoich }}$ iso- 
line is very corrugated due to the turbulent structures occurring at this location. At $t=2.0 \mathrm{~ms}$, a bulge (i.e. a convex interface towards the oxidizer stream) is visible, forming at approximately $z=36 \mathrm{~mm}$ and $\mathrm{x}=5 \mathrm{~mm}$. Subsequently, the curvature of the jet-coflow-interface increases and the bulge almost separates from the main jet region. Mixing increases inside the bulge, which is seen by a drop in the peak mixture fraction from $\xi \approx 0.2$ to $\xi \approx 0.1$ between $2.0 \mathrm{~ms}$ and $2.2 \mathrm{~ms}$. At $t=2.2 \mathrm{~ms}$ an ignition kernel forms at approximately $\mathrm{z}=37 \mathrm{~mm}$ and $\mathrm{x}=7 \mathrm{~mm}$. This ignition kernel grows in the subsequent frames and is seen penetrating into a concave pocket left and upstream of the bulge where the ignition kernel initially formed. It also is seen that the ignition kernel forms outside the $\xi_{\text {stoich }}$ iso-line, suggesting that the kernel initiates at a very lean mixture fraction. The so-called "most-reactive mixture-fraction", $\xi_{m r}$, where ignition is expected to occur based on DNS results [36] is an order of magnitude lower than $\xi_{\text {stoich }}$ for the present fuel/oxidizer conditions [29]. Due to the extremely low fuel concentration at $\xi_{m r}$, the dynamic range of the Rayleigh-scattering measurements is too small to quantitatively measure the mixture fraction field at these ultra-lean conditions. The dynamic range of the system is limited by the signal-to-noise ratio in the coflow, which is dominated by the read-out noise of the camera. Apparent mixture fractions up to $\xi=0.015$ due to finite noise effects were detected in coflow regions where no fuel is present (i.e. before the start of the fuel injection) and represent the resolution limit of the measurement system in terms of the mixture fraction. The standard deviation of the mixture fraction in the coflow region was $\xi_{S D}=0.004$. Thus, the mixture fraction measurement resolution is approximately half of the stoichiometric mixture fraction. Oldenhof et al. [17] observed that flame structures resided in regions where the velocity is dominated by the lower coflow velocity; in this case, flame structures are also expected to occur at very lean mixture fractions. Similarly, in the current experiment, the propagation velocity of ignition kernels is quite low, suggesting that the region where the kernels develop is dominated by the lower coflow velocity. Figure 13 shows the same ignition event as in Fig. 11 and Fig. 12, as visualized by the square of the mixture fraction gradient as a marker for the scalar dissipation rate. At $t=2.1 \mathrm{~ms}$, the bulge of the fuel jet that will eventually lead to the igniting fluid element, is seen in a region with high scalar dissipation. In the next frame, at $t=2.2 \mathrm{~ms}$, the forming ignition kernel is seen (as represented by the white temperature iso-contour) at a location at the jet-coflow-interface where the scalar dissipation has decreased significantly. Subsequently, the ignition kernel propagates along a very lean mixture with low scalar dissipation. At $t=2.4 \mathrm{~ms}$, after the ignition kernel has grown significantly, a reaction is seen (visualized by a temperature rise) adjacent to locations with high scalar dissipation. However, at this time, the extent of the kernel outside the measurement plane cannot be neglected and information of the scalar dissipation along the complete kernel surface is missing.

\subsection{Statistical evaluation on the influence of scalar dissipation rate and mixture fraction on auto- ignition}


To extract further statistical information on the role of scalar dissipation rate and local mixture fraction on auto-ignition, the basic behavior of the auto-ignition kernels is studied. Figure 14 shows the probability density function (PDF) of the ignition height for 300 examined auto-ignition events as determined from the two-camera CL imaging. The maximum of the PDF is at $\mathrm{z}=38.9 \mathrm{~mm}$, close to the mean of the ignition height of $z=39.3 \mathrm{~mm}$. The standard deviation is $5.7 \mathrm{~mm}$ (or $14.5 \%$ ), and the measured ignition heights span approximately $30 \mathrm{~mm}$. Figure 15 shows the PDF of the ignition time. Here the maximum of the PDF is at $t=2.42 \mathrm{~ms}$ (same as the mean value) with a standard deviation of $0.21 \mathrm{~ms}$ (or $8.7 \%$ ). Similar to the ignition height, the ignition time also has a significant scatter, with ignition times spanning a range of approximately $1 \mathrm{~ms}$ (minimum to maximum). However, the relative standard deviation of the ignition time is only approximately half of the relative standard deviation of the ignition height. As already observed in the previous image sequences of ignition events, the mixture fraction and scalar dissipation rate seem to have a significant impact on the auto-ignition locations.

To further asses this aspect, a joint probability density function (JPDF) of scalar dissipation rate and mixture fraction at the spatial and temporal range at which auto-ignition occurred has been computed based on all 300 studied ignition event and is shown in Fig. 16. The range of axial positions considered for the JPDF is shown as the grey shaded area in Fig. 14, and the temporal range considered is shown as the grey shaded area in Fig. 15. The observed ignition kernels occurred at radial locations between $|x|=3 \mathrm{~mm}$ and $|x|=9 \mathrm{~mm}$, and thus this area is considered for the JPDF. Since the jet fluid was not always present within the field of view, the maximum of the JPDF occurs at $\xi=0$ and $(\nabla \xi)^{2}=0$. However, the range of mixture fraction and scalar dissipation rate combinations spans a wide area.

In approximately $7.5 \%$ of the measured ignition events, the first observed ignition kernel occurred within the laser light sheet plane. To fulfill the criteria of occurring within the laser light sheet plane, the centroid of an ignition kernel (as detected by $\mathrm{OH}^{*} \mathrm{CL}$ camera 2) had to be within $\pm 0.75 \mathrm{~mm}$ of the laser light sheet plane. Note that only ignition kernels with a size larger than $2 \mathrm{~mm}^{2}$ (corresponding to a radial extent of approximately $1.5 \mathrm{~mm}$ ) could be detected; smaller detected events were considered as noise, as described above. Out of the $7.5 \%$ of the ignition kernels that occurred within the laser light sheet plane, approximately $90 \%$ occurred at an axial location that was covered by the laser light sheet. The remaining kernels either occurred above or below the field of view (see the grey shaded area in Fig. 14, which covers approximately the axial extent of the laser light sheet).

In order to assess the influence of mixture fraction and scalar dissipation rate on auto-ignition, the mean mixture fraction and scalar dissipation rate at the location of the kernel formation was calculated immediately prior to the onset of auto-ignition (one frame or $100 \mu \mathrm{s}$ before the first detected ignition kernel), as represented by the $T=1560 \mathrm{~K}$ iso-contour of the temperature measurements, and were 
plotted in the JPDF in Fig. 16 (white closed symbols). The black closed symbol corresponds to the ignition event shown in Figs. 11 - 13. Nearly all of the observed ignition kernels occurred at very lean mixture fractions and low values of scalar dissipation rate. These observations support previous assertions of the importance of the most reactive mixture fraction and its occurrence at very lean mixtures [36] and the direct influence of increased scalar dissipation rate on auto-ignition delay times [29]. Only two of the detected kernels occurred at higher values of mixture fraction and scalar dissipation rate, which is most likely due to their vicinity to decaying mixture fraction and high scalar dissipation rate structures, similar to the image sequence in Figs. $11-13$. 


\section{Conclusions}

Time-resolved planar measurements of mixture fraction, temperature and scalar dissipation rate during pulsed injection of a methane jet into a hot oxidizer and the subsequent auto-ignition were performed in the DLR Jet in Hot Coflow Burner (DLR JHC). The measurements revealed that the current experimental configuration has very reproducible boundary conditions and thus is suitable for a detailed study of auto-ignition in a simple model system. Such measurements can provide high-quality validation data for numerical simulations, which are already in use [60]. A detailed analysis of the behavior of the impulsively-started jet was performed. It was found that the individual injection events were extremely reproducible, with a very low scatter of the jet tip position throughout 50 examined injection events. The jet tip position scaled proportionally to time $(t)$ at lower axial locations and scaled as $\sim t^{1 / 2}$ at higher axial positions, as expected from previous studies [33, 59]. For a fixed axial position, the fuel jet was found to transition to steady-state behavior less than $1 \mathrm{~ms}$ after the jet tip has passed the axial location and prior to the onset of auto-ignition. Auto-ignition was observed to occur at the outmost periphery of the fuel jet at mixture fractions much leaner as the stoichiometric mixture fraction. Following the time history of the scalar dissipation rate field, it was observed that ignition occurs at locations with low scalar dissipation. Locations having conditions favorable for auto-ignition only were observed at axial locations of $z>30 \mathrm{~mm}$. A joint probability density function analysis of mixture fraction and scalar dissipation prior to the onset of auto-ignition revealed further statistical information on the propensity of ignition kernels to occur at locations of low scalar dissipation rate and very lean mixture fractions below the stoichiometric mixture fraction. Future investigations will focus on the influence of temperature on the mixing field and auto-ignition sites as well as on different fuels and fuel blends.

\section{Acknowledgments}

The authors wish to thank Campbell Carter of the Air Force Research Laboratory and Tonghun Lee of the University of Illinois for the loan of high-speed imaging equipment. Financial support within the DLR projects IVTAS and PIZ-0182-737 is gratefully acknowledged. Work at Ohio State was supported by the Combustion Energy Frontier Research Center, funded by DOE, Office of Science, BES under Award DE-SC0001198. 


\section{References}

[1] A. Koch, C. Naumann, W. Meier, M. Aigner Experimental Study and Modeling of Autoignition of Natural Gas/Air-Mixtures Under Gas Turbine Relevant Conditions, Proc. ASME Turbo Expo (2005) GT2005-68405.

[2] F. Güthe, J. Hellat, P. Flohr, The Reheat Concept: The Proven Pathway to Ultralow Emissions and High Efficiency and Flexibility, J. Eng. Gas Turbines Power 131 (2009) 021503.

[3] I. Boxx, M. Stöhr, C. Carter, W. Meier, Temporally resolved planar measurements of transient phenomena in a partially pre-mixed swirl flame in a gas turbine model combustor, Combust. Flame 157 (2010) 1510-1525.

[4] O. Lammel, M. Stöhr, P. Kutne, C. Dem, W. Meier, M. Aigner, Experimental Analysis of Confined Jet Flames by Laser Measurement Techniques, J. Eng. Gas Turbines Power 134 (2012) 041506.

[5] A. Cavaliere, M. de Joannon, MILD combustion, Prog. Energy Combust. Sci. 30 (2004) 329366.

[6] M. Katsuki, T. Hasegawa, The science and technology of combustion in highly preheated air, Symp. (Int.) Combust. 27 (1998) 3135-3146.

[7] M. de Joannon, P. Sabia, G. Sorrentino, A. Cavaliere, Numerical study of mild combustion in hot diluted diffusion ignition (HDDI) regime, Proc. Combust. Inst. 32 (2009) 3147-3154.

[8] C. N. Markides, E. Mastorakos, An experimental study of hydrogen autoignition in a turbulent co-flow of heated air, Proc. Combust. Inst. 30 (2005) 883-891.

[9] F. Eitel, J. Pareja, D. Geyer, A. Johchi, F. Michel, W. Elsäßer, A. Dreizler, A novel plasma test rig for auto-ignition studies of turbulent non-premixed flows, Exp. Fluids 56 (2015) 186.

[10] R. Cabra, T. Myhrvold, J. Y. Chen, R. W. Dibble, A. N. Karpetis, R. S. Barlow, Simultaneous Laser Raman-Rayleigh-LIF Measurements and Numerical Modeling Results of a Lifted Turbulent H2/N2 Jet Flame in a Vitiated Coflow, Proc. Combust. Inst. 29 (2002) 1881-1888.

[11] R. Cabra, J. Y. Chen, R. W. Dibble, A. N. Karpetis, R. S. Barlow, Lifted methane-air jet flames in a vitiated coflow, Combust. Flame 143 (2005) 491-506.

[12] B. B. Dally, A. N. Karpetis, R. S. Barlow, Structure of turbulent non-premixed jet flames in a diluted hot coflow, Proc. Combust. Inst. 29 (2002) 1147-1154.

[13] R. L. Gordon, A. R. Masri, S. B. Pope, G. M. Goldin, Transport budgets in turbulent lifted flames of methane autoigniting in a vitiated co-flow, Combust. Flame 151 (2007) 495-511.

[14] P. R. Medwell, P. A. M. Kalt, B. B. Dally, Simultaneous imaging of $\mathrm{OH}$, formaldehyde, and temperature of turbulent nonpremixed jet flames in a heated and diluted coflow, Combust. Flame 148 (2007) 48-61.

[15] R. L. Gordon, A. R. Masri, E. Mastorakos, Simultaneous Rayleigh temperature, $\mathrm{OH}$ - and $\mathrm{CH} 2 \mathrm{O}-$ LIF imaging of methane jets in a vitiated coflow, Combust. Flame 155 (2008) 181-195.

[16] E. Oldenhof, M. J. Tummers, E. H. van Veen, D. J. E. M. Roekaerts, Ignition kernel formation and lift-off behaviour of jet-in-hot-coflow flames, Combust. Flame 157 (2010) 1167-1178.

[17] E. Oldenhof, M. J. Tummers, E. H. van Veen, D. J. E. M. Roekaerts, Transient response of the Delft jet-in-hot coflow flames, Combust. Flame 159 (2012) 697-706.

[18] P. R. Medwell, B. B. Dally, Experimental Observation of Lifted Flames in a Heated and Diluted Coflow, Energy Fuels 26 (2012) 5519-5527.

[19] B. Böhm, C. Heeger, R. L. Gordon, A. Dreizler, New Perspectives on Turbulent Combustion: Multi-Parameter High-Speed Planar Laser Diagnostics, Flow Turbul. Combust. 86 (2011) 313-341.

[20] A. Dreizler, B. Bohm, Advanced laser diagnostics for an improved understanding of premixed flame-wall interactions, Proc. Combust. Inst. 35 (2015) 37-64.

[21] V. Sick, High speed imaging in fundamental and applied combustion research, Proc. Combust. Inst. 34 (2013) 3509-3530.

[22] R. Sadanandan, D. Markus, R. Schießl, U. Maas, J. Olofsson, H. Seyfried, M. Richter, M. Alden, Detailed investigation of ignition by hot gas jets, Proc. Combust. Inst. 31 (2007) 719-726. 
[23] G. Fast, D. Kuhn, A. G. Class, U. Maas, Auto-ignition during instationary jet evolution of dimethyl ether (DME) in a high-pressure atmosphere, Combust. Flame 156 (2009) 200-213.

[24] J. Fleck, P. Griebel, A. M. Steinberg, M. Stöhr, M. Aigner, A. Ciani, Autoignition Limits of Hydrogen at Relevant Reheat Combustor Operating Conditions, J. Eng. Gas Turbines Power 134 (2012) 041502.

[25] J. M. Fleck, P. Griebel, A. M. Steinberg, C. M. Arndt, M. Aigner, Auto-ignition and flame stabilization of hydrogen/natural gas/nitrogen jets in a vitiated cross-flow at elevated pressure, Int. J. Hydrogen Energy 38 (2013) 16441-16452.

[26] J. M. Fleck, P. Griebel, A. M. Steinberg, C. M. Arndt, C. Naumann, M. Aigner, Autoignition of hydrogen/nitrogen jets in vitiated air crossflows at different pressures, Proc. Combust. Inst. 34 (2013) 3185-3192.

[27] W. Meier, I. Boxx, C. Arndt, M. Gamba, N. Clemens, Investigation of Auto-Ignition of a Pulsed Methane Jet in Vitiated Air Using High-Speed Imaging Techniques, J. Eng. Gas Turbines Power 133 (2011) 021504.

[28] C. M. Arndt, J. D. Gounder, W. Meier, M. Aigner, Auto-ignition and flame stabilization of pulsed methane jets in a hot vitiated coflow studied with high-speed laser and imaging techniques, Appl. Phys. B 108 (2012) 407-417.

[29] C. M. Arndt, R. SchießI, J. D. Gounder, W. Meier, M. Aigner, Flame stabilization and autoignition of pulsed methane jets in a hot coflow: Influence of temperature, Proc. Combust. Inst. 34 (2013) 1483-1490.

[30] M. J. Papageorge, C. Arndt, F. Fuest, W. Meier, J. A. Sutton, High-speed mixture fraction and temperature imaging of pulsed, turbulent fuel jets auto-igniting in high-temperature, vitiated coflows, Exp. Fluids 55 (2014) 1763.

[31] B. Johannessen, A. North, R. Dibble, T. Lovas, Experimental studies of autoignition events in unsteady hydrogen-air flames, Combust. Flame 162 (2015) 3210-3219.

[32] P. O. Witze The impulsively started incompressible turbulent jet, Report No. SAND80-8617 Sandia National Laboratories, Livermore, CA, USA 1980.

[33] A. Joshi, W. Schreiber, An experimental examination of an impulsively started incompressible turbulent jet, Exp. Fluids 40 (2006) 156-160.

[34] N. Soulopoulos, Y. Hardalupas, A. M. K. P. Taylor, Scalar dissipation rate measurements in a starting jet, Exp. Fluids 55 (2014) 1685.

[35] L. Ma, Q. C. Lei, Y. Wu, T. M. Ombrello, C. D. Carter, 3D measurements of ignition processes at $20 \mathrm{kHz}$ in a supersonic combustor, Appl. Phys. B 119 (2015) 313-318.

[36] E. Mastorakos, Ignition of Turbulent Non-Premixed Flames, Prog. Energy Combust. Sci. 35 (2009) 57-97.

[37] S. Cao, T. Echekki, Autoignition in nonhomogeneous mixtures: Conditional statistics and implications for modeling, Combust. Flame 151 (2007) 120-141.

[38] J. Doom, K. Mahesh, Direct numerical simulation of auto-ignition of a hydrogen vortex ring reacting with hot air, Combust. Flame 156 (2009) 813-825.

[39] S. Sreedhara, K. N. Lakshmisha, Direct numerical simulation of autoignition in a nonpremixed, turbulent medium, Proc. Combust. Inst. 28 (2000) 25-33.

[40] E. Mastorakos, T. A. Baritaud, T. J. Poinsot, Numerical simulations of autoignition in turbulent mixing flows, Combust. Flame 109 (1997) 198-223.

[41] A. Viggiano, V. Magi, A 2-D investigation of $n$-heptane autoignition by means of direct numerical simulation, Combust. Flame 137 (2004) 432-443.

[42] T. Echekki, J. H. Chen, Direct numerical simulation of autoignition in non-homogeneous hydrogen-air mixtures, Combust. Flame 134 (2003) 169-191.

[43] R. Hilbert, D. Thévenin, Autoignition of turbulent non-premixed flames investigated using direct numerical simulation, Combust. Flame 128 (2002) 22-37.

[44] H. G. Im, J. H. Chen, C. K. Law, Ignition of hydrogen-air mixing layer in turbulent flows, Symp. (Int.) Combust. 27 (1998) 1047-1056. 
[45] J. A. van Oijen, Direct numerical simulation of autoigniting mixing layers in MILD combustion, Proc. Combust. Inst. 34 (2013) 1163-1171.

[46] Y. Wang, C. J. Rutland, Direct numerical simulation of ignition in turbulent $\mathrm{n}$-heptane liquidfuel spray jets, Combust. Flame 149 (2007) 353-365.

[47] S. G. Kerkemeier, C. N. Markides, C. E. Frouzakis, K. Boulouchos, Direct numerical simulation of the autoignition of a hydrogen plume in a turbulent coflow of hot air, J. Fluid Mech. 720 (2013) 424-456.

[48] B. Thurow, N. B. Jiang, W. Lempert, Review of ultra-high repetition rate laser diagnostics for fluid dynamic measurements, Meas. Sci. Technol. 24 (2013) 012002.

[49] T. A. McManus, M. J. Papageorge, F. Fuest, J. A. Sutton, Spatio-temporal characteristics of temperature fluctuations in turbulent non-premixed jet flames, Proc. Combust. Inst. 35 (2015) 11911198.

[50] M. J. Papageorge, T. A. McManus, F. Fuest, J. A. Sutton, Recent advances in high-speed planar Rayleigh scattering in turbulent jets and flames: increased record lengths, acquisition rates, and image quality, Appl. Phys. B 115 (2014) 197-213.

[51] R. A. Patton, K. N. Gabet, N. Jiang, W. R. Lempert, J. A. Sutton, Multi-kHz mixture fraction imaging in turbulent jets using planar Rayleigh scattering, Appl. Phys. B 106 (2012) 457-471.

[52] R. A. Patton, K. N. Gabet, N. Jiang, W. R. Lempert, J. A. Sutton, Multi-kHz temperature imaging in turbulent non-premixed flames using planar Rayleigh scattering, Appl. Phys. B 108 (2012) 377-392.

[53] K. N. Gabet, N. Jiang, W. R. Lempert, J. A. Sutton, Demonstration of high-speed 1D Raman scattering line imaging, Appl. Phys. B 101 (2010) 1-5.

[54] F. Fuest, M. J. Papageorge, W. R. Lempert, J. A. Sutton, Ultrahigh laser pulse energy and power generation at $10 \mathrm{kHz}$, Opt. Lett. 37 (2012) 3231-3233.

[55] S. Prucker, W. Meier, W. Stricker, A flat flame burner as calibration source for combustion research: Temperatures and species concentrations of premixed H2/air flames, Rev. Sci. Instrum. 65 (1994) 2908-2911.

[56] S. Gordon, B. J. McBride, Computer Program for Calculation of Complex Chemical Equilibrium Compositions and Applications - I. Analysis, NASA Reference Publication 1311 (1994)

[57] J. Prause, B. Noll, M. Aigner, K. Syed, Sensitivity Analysis of Auto-Ignition Simulation at Gas Turbine Operating Conditions, J. Eng. Gas Turbines Power 137 (2015) 102601.

[58] E. Oldenhof, M. J. Tummers, E. H. van Veen, D. J. E. M. Roekaerts, Role of entrainment in the stabilisation of jet-in-hot-coflow flames, Combust. Flame 158 (2011) 1553-1563.

[59] P. G. Hill, P. Ouellette, Transient turbulent gaseous fuel jets for diesel engines, J. Fluid Eng. 121 (1999) 93-101.

[60] A. Fiolitakis, P. Ess, P. Gerlinger, M. Aigner, Anwendung eines Transportgleichungs-PDFVerfahrens zur Berechnung der Selbstzündung eines Methan-Freistrahles, VDI-Berichte 2267 (2015) 617-628. 


\section{Tables}

\begin{tabular}{ccccccccccc}
\hline & \multicolumn{10}{c}{ Coflow } \\
\cline { 2 - 10 }$\dot{m}_{C H_{4}}$ & $\dot{m}_{\text {air }}$ & $\dot{m}_{H_{2}}$ & $\varphi_{\text {coflow }}$ & $\xi_{\text {stoich }}$ & $T_{\text {coflow }}$ & $T_{a d}$ & $X_{N 2}$ & $X_{O 2}$ & $X_{H 2 O}$ & $X_{O H}$ \\
{$[\mathrm{~g} / \mathrm{min}]$} & {$[\mathrm{g} / \mathrm{min}]$} & {$[\mathrm{g} / \mathrm{min}]$} & {$[-]$} & {$[-]$} & {$[\mathrm{K}]$} & {$[\mathrm{K}]$} & {$[-]$} & {$[-]$} & {$[-]$} & {$[-]$} \\
\hline 12.4 & 285 & 3.86 & 0.465 & 0.0297 & 1490 & 1564 & 0.712 & 0.102 & 0.178 & $8.2 \times 10^{-5}$ \\
\hline
\end{tabular}

Table 1 


\section{Table Captions}

Table 1: Operating conditions for the matrix burner and the transient jet. $T_{a d}$ is the adiabatic flame temperature calculated for a reactant gas temperature of $290 \mathrm{~K}, T_{\text {coflow }}$ is the measured coflow temperature at $\mathrm{z}=40 \mathrm{~mm}$ and $\mathrm{x}=10 \mathrm{~mm}$. $\xi_{\text {stoich }}$ is the stoichiometric mixture fraction for the methane / coflow mixture. The mole fractions indicate the composition of the coflow, calculated for an equilibrium temperature of $1490 \mathrm{~K}$. 


\section{Figure Captions}

Figure 1: Schematic of the DLR Jet in Hot Coflow (DLR JHC) Burner.

Figure 2: Experimental Setup.

Figure 3: Radial temperature profiles at different heights above the burner. The dashed line corresponds to the adiabatic flame temperature, $T_{a d}$, at this operating condition.

Figure 4: Probability density functions (PDFs) of temperature (a) for different axial locations averaged at a radial location $\mathrm{x}=10 \pm 2.5 \mathrm{~mm}$ and (b) for different radial locations $\mathrm{x}$ $\pm 2.5 \mathrm{~mm}$ at $\mathrm{z}=40 \mathrm{~mm}$.

Figure 5: Mosaic of the mixture fraction field during the transient fuel injection. Each image row corresponds to one individual injection event. Note the logarithmic scale colormap.

Figure 6: Mosaic of the temperature field during the transient fuel injection. Each image row corresponds to one individual injection event.

Figure 7: Mosaic of the squared mixture fraction gradient field as a marker for the scalar dissipation rate during the transient fuel injection. Each image row corresponds to one individual injection event. Note the logarithmic scale colormap.

Figure 8: Jet penetration vs. time. The black dots correspond to the mean axial location of the jet tip for 50 measurements; the solid blue line corresponds to a linear fit for $\mathrm{z}<30 \mathrm{~mm}$ and serves as an extrapolation for axial locations where no measurements could be performed. The solid red line corresponds to a fit $\sim t^{1 / 2}$ for $\mathrm{z}>30 \mathrm{~mm}$.

Figure 9: Mean mixture fraction of the fuel jet at different axial locations for one individual (dashed line) and average of 50 individual injection events (solid line).

Figure 10: Temporal evolution of the mixture fraction profile at $\mathrm{z}=40 \mathrm{~mm}$ during transient fuel injection.

Figure 11: Mixture fraction field during the development of an auto-ignition kernel. Note the logarithmic colorbar. The red contour indicates an iso-contour of the stoichiometric mixture fraction; and the white contour indicates the iso-contour of a temperature $T=$ $1560 \mathrm{~K}$.

Figure 12: Temperature field during the development of an auto-ignition kernel. The black contour indicates the iso-contour of the stoichiometric mixture fraction and the white contour indicates the iso-contour of a temperature $T=1560 \mathrm{~K}$.

Figure 13: Squared gradient of the mixture fraction as marker for the scalar dissipation rate during the development of an auto-ignition kernel. Note the logarithmic colorbar. The white contour indicates the iso-contour of a temperature $T=1560 \mathrm{~K}$.

Figure 14: Probability density function (PDF) of the auto-ignition height as measured with the $\mathrm{OH}^{*}$ chemiluminescence. The grey shaded area represents the region in which the joint PDF of mixture fraction and scalar dissipation in Figure 16 was calculated. 
Figure 15: Probability density function (PDF) of the auto-ignition time as measured with the $\mathrm{OH}^{*}$ chemiluminescence. The grey shaded area represents the region in which the joint PDF of mixture fraction and scalar dissipation in Figure 16 was calculated.

Figure 16: Joint probability density function (JPDF) of scalar dissipation rate (as estimated by the square of the gradient of the mixture fraction) and mixture fraction at the locations at which auto-ignition occurs. The white markers indicate scalar dissipation and mixture fraction at the locations of the measured ignition kernels immediately prior to the onset of autoignition. The black marker corresponds to the image series shown in Figs. 11 - 13. 
Figure's

Figure 1

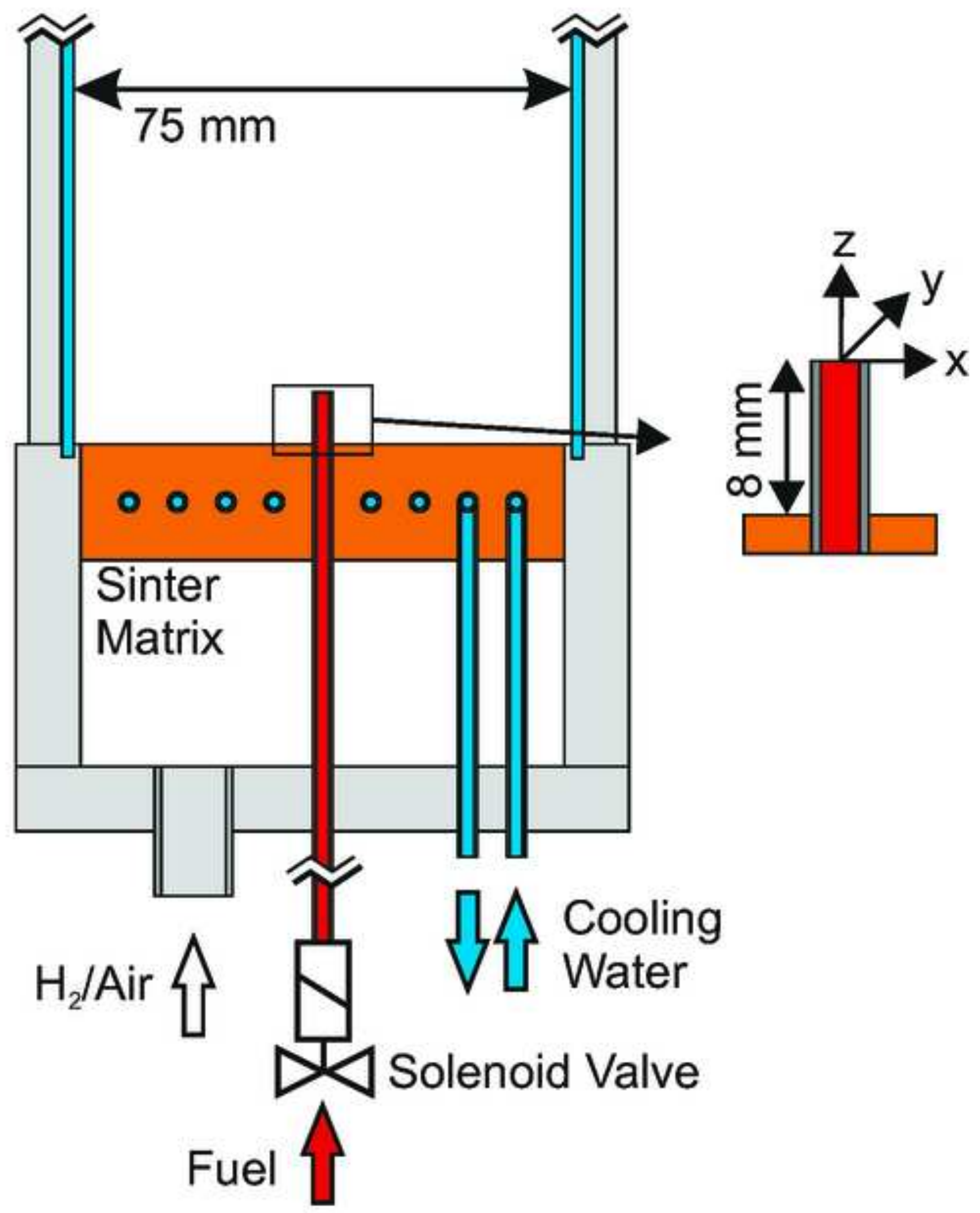


Figure 2

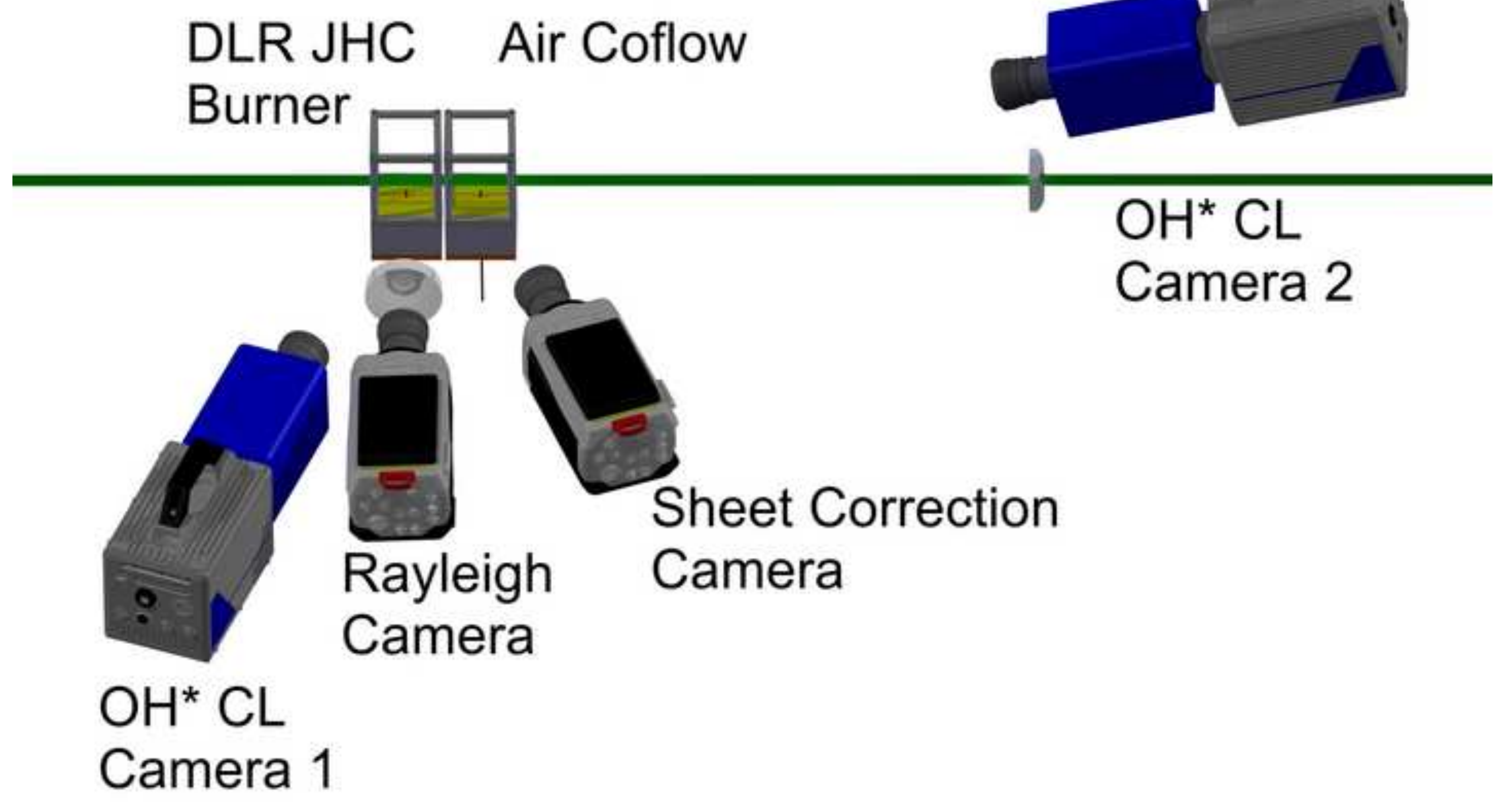


Figure 3

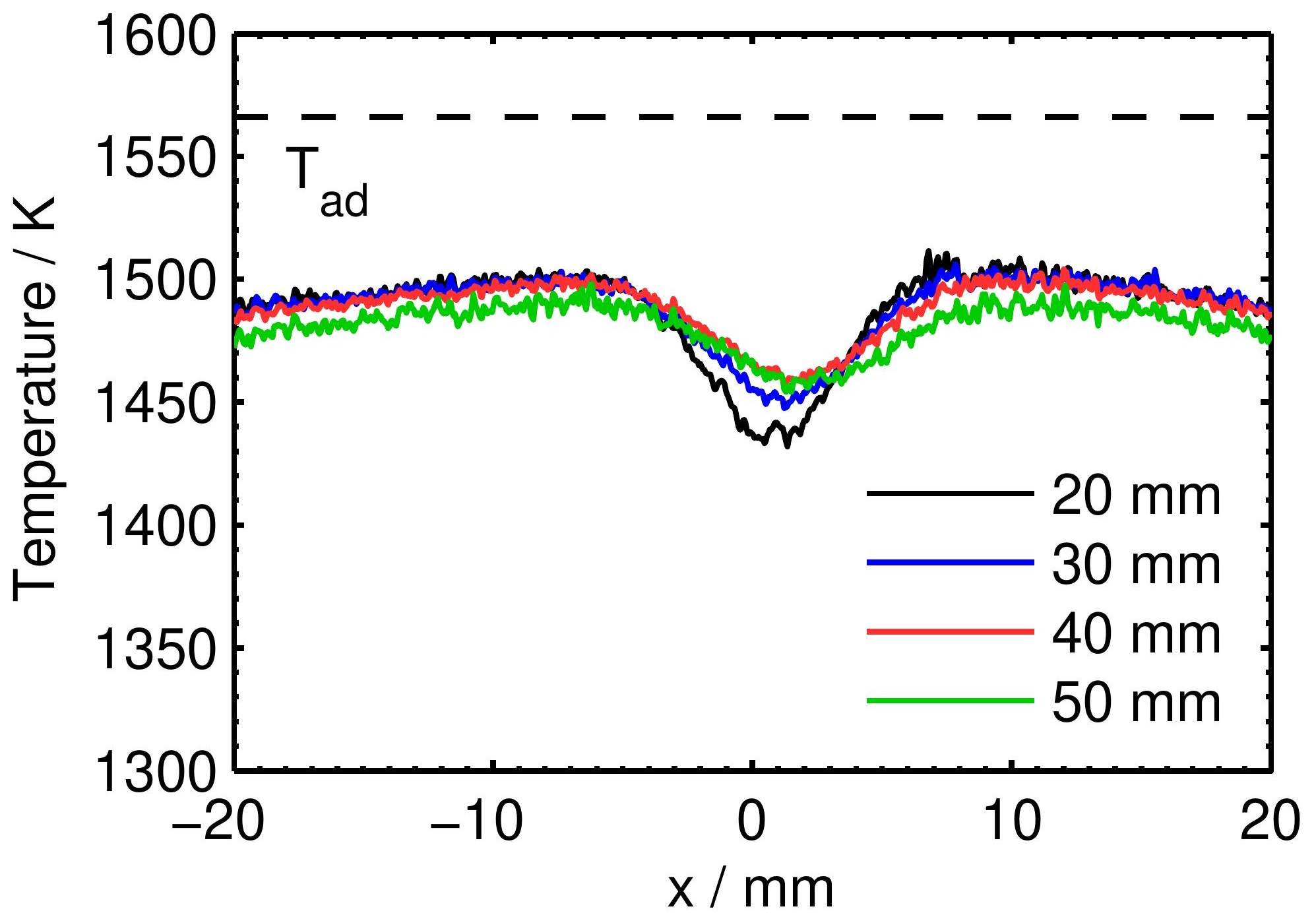


Figure $4 a$

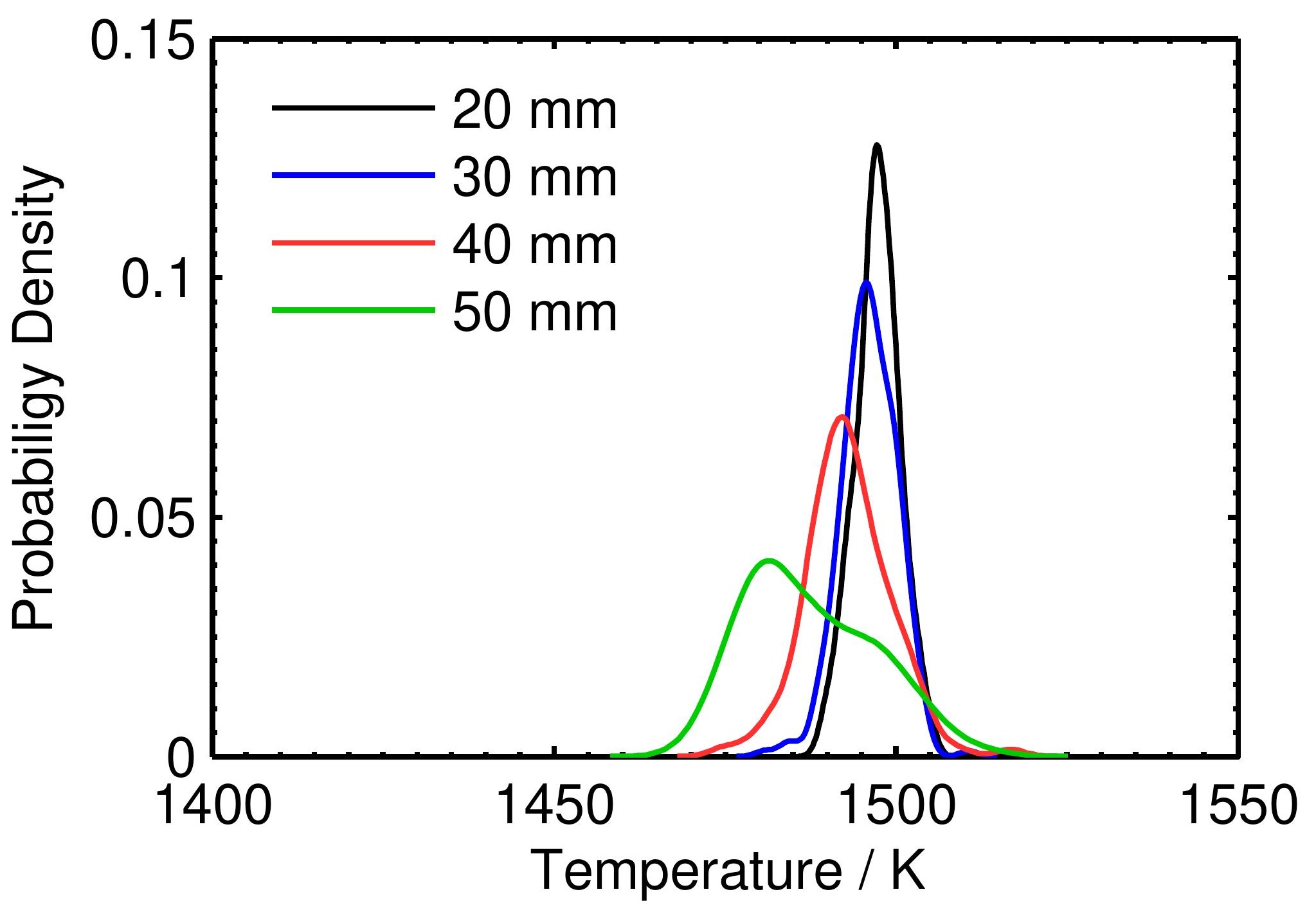


Figure $4 b$

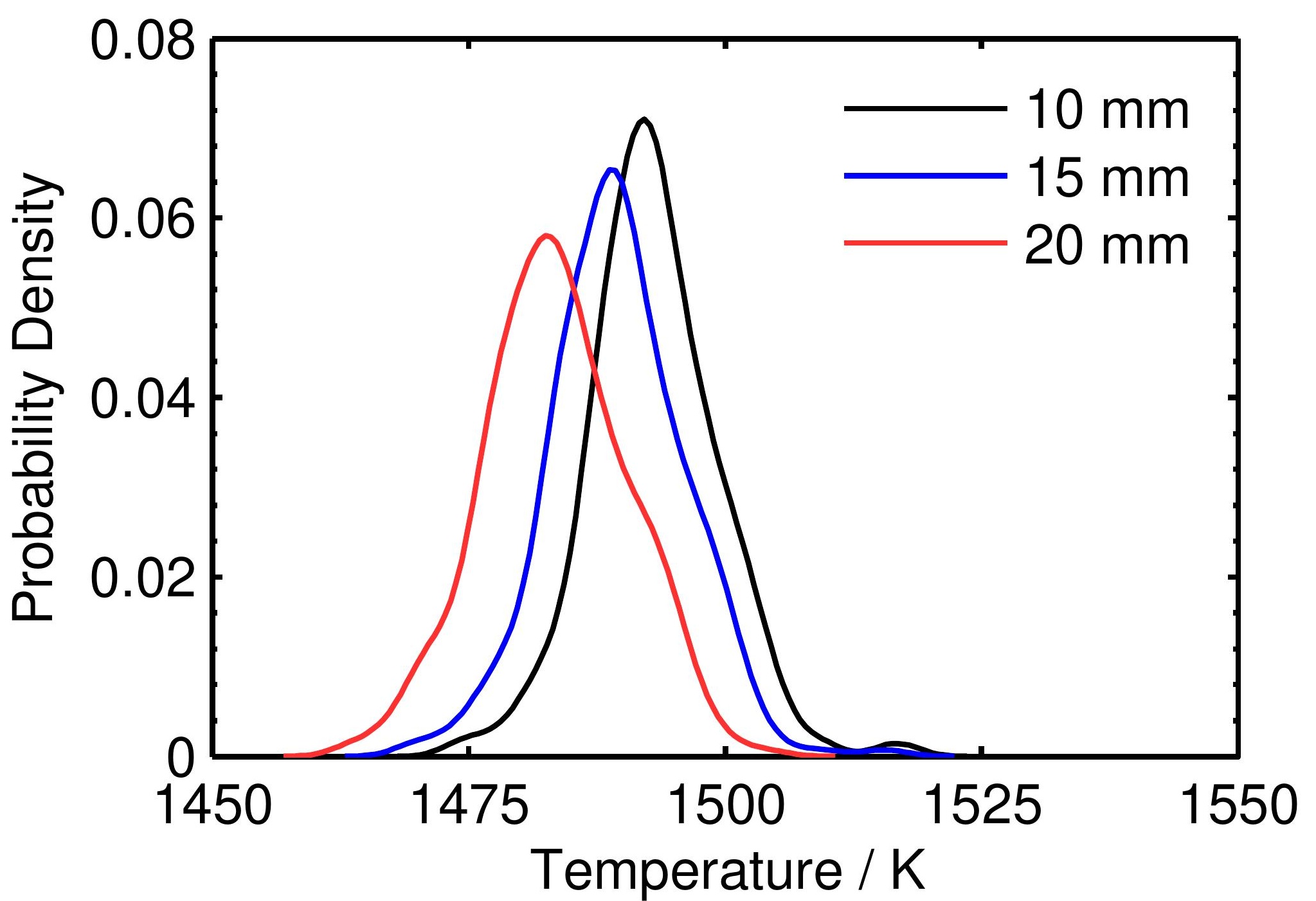


Figure 5

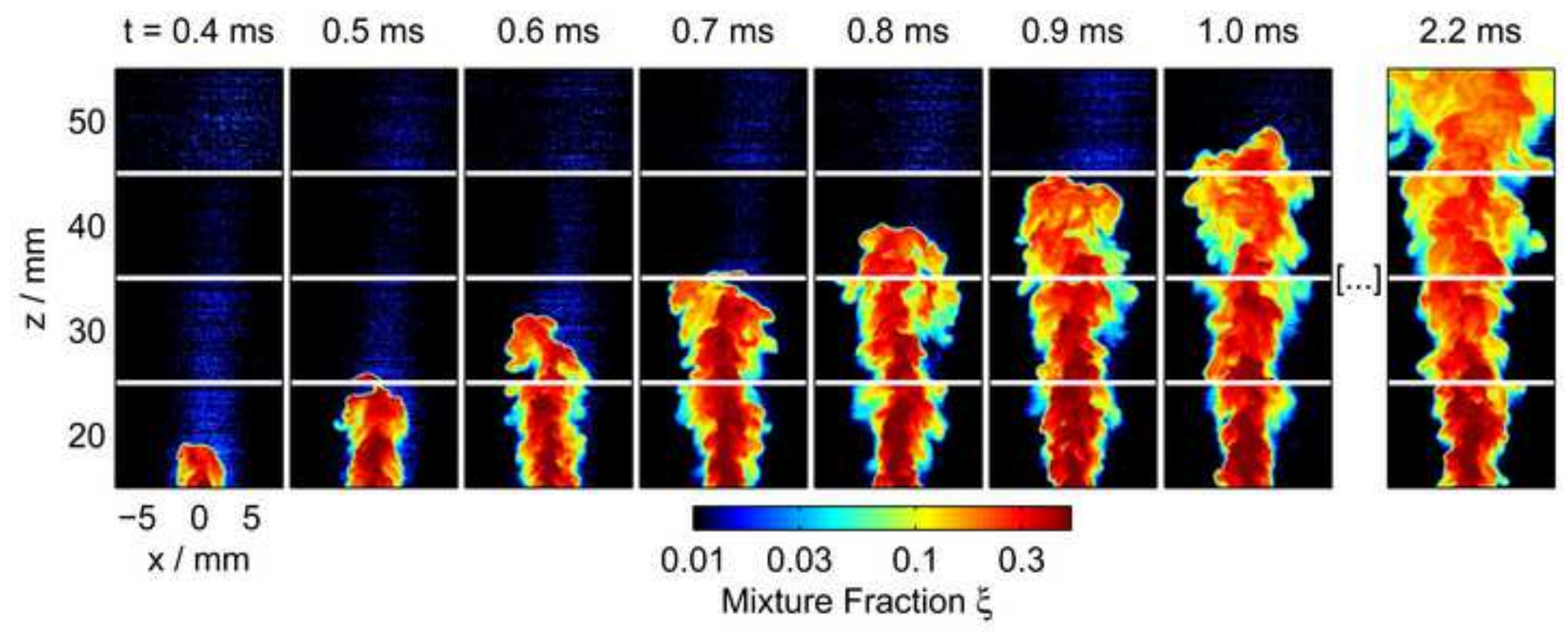


Figure 6

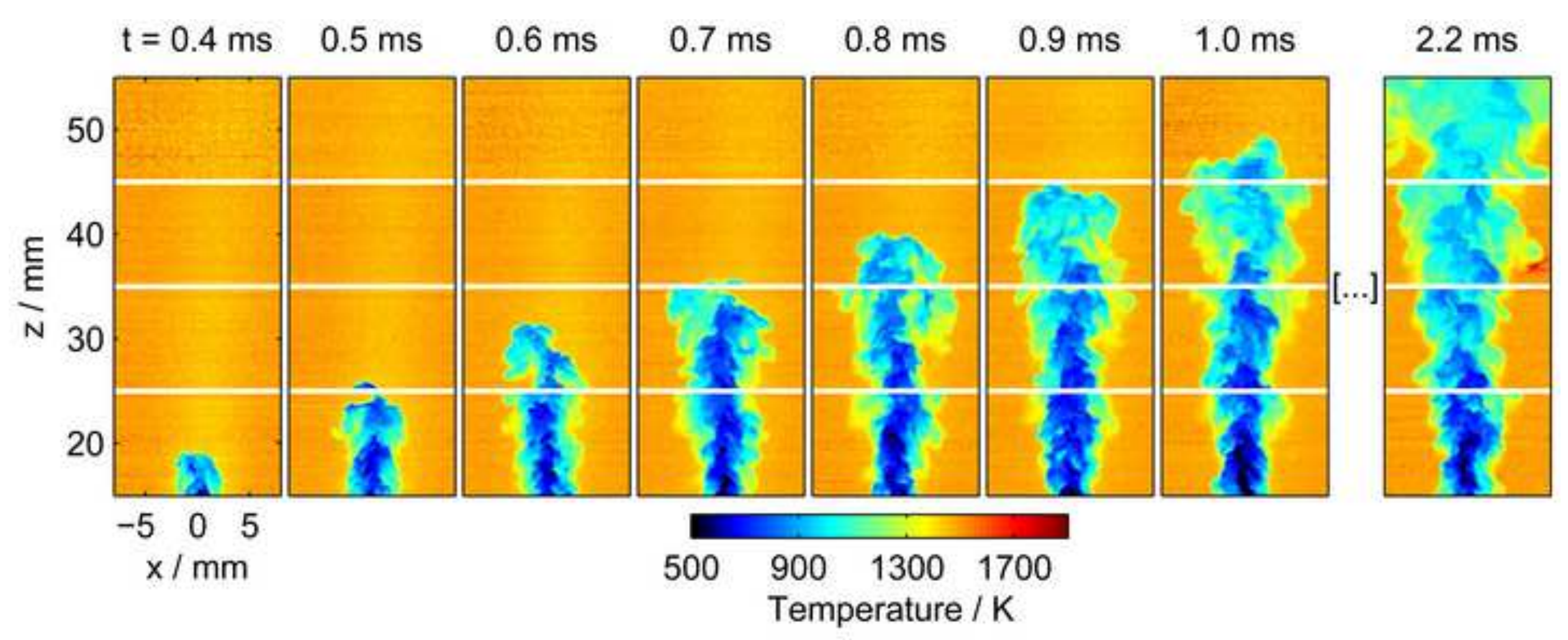


Figure 7

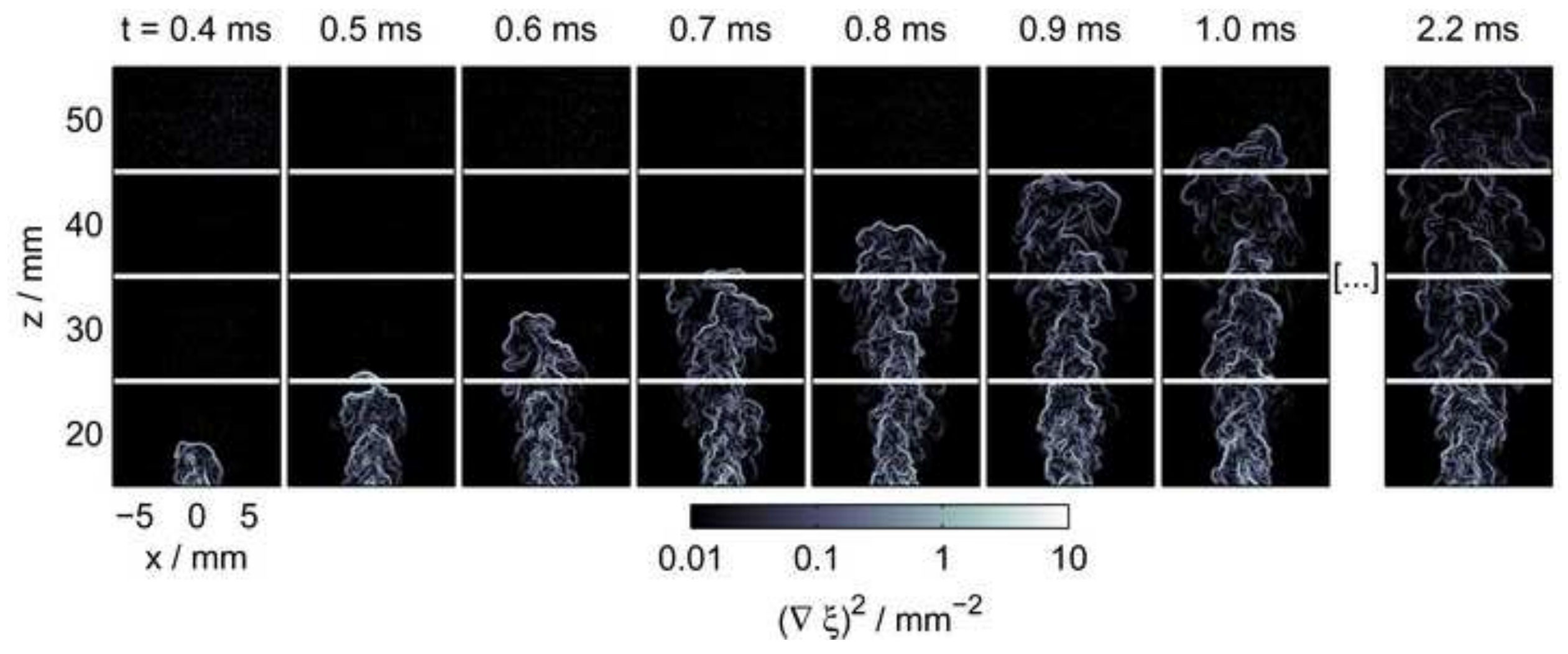


Figure 8

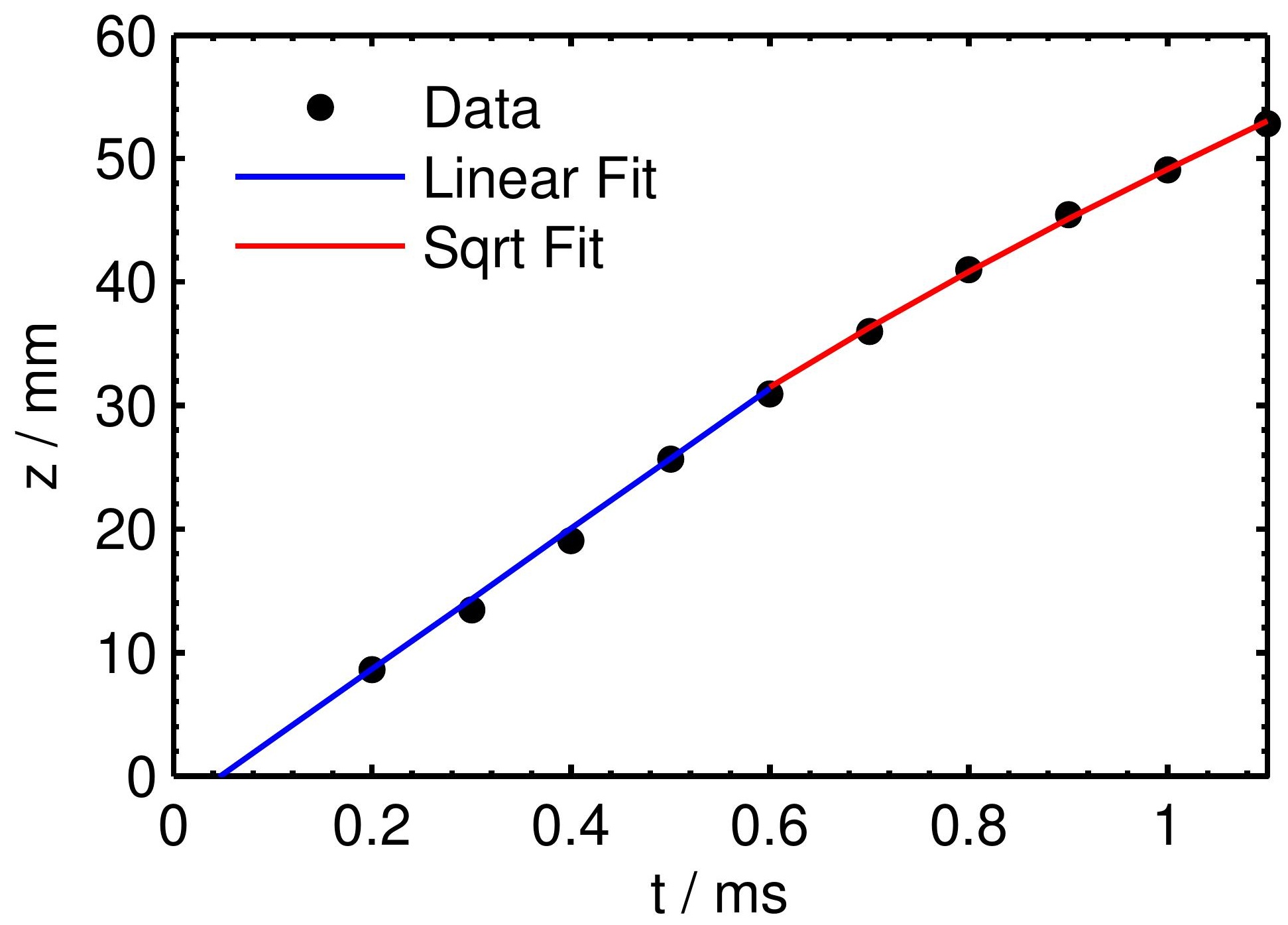


Figure 10

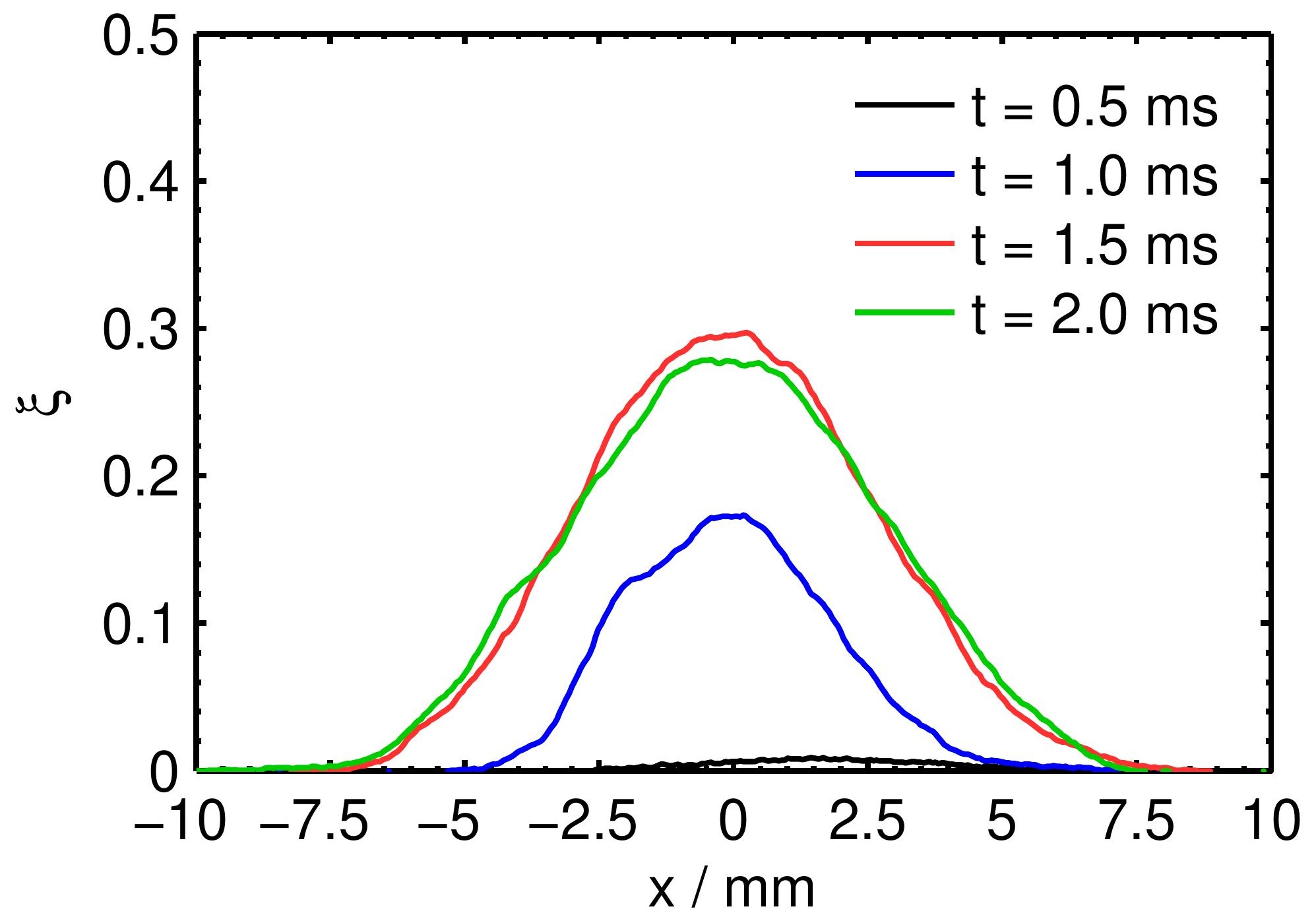


Figure 11

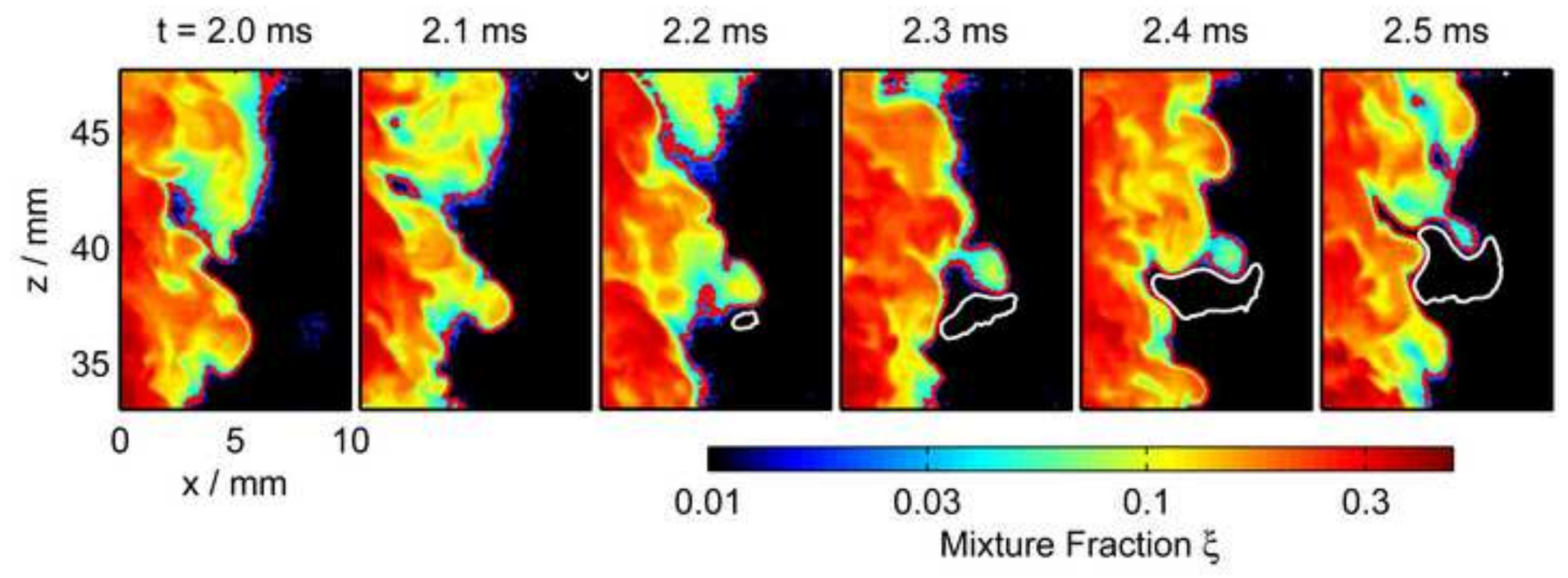


Figure 12

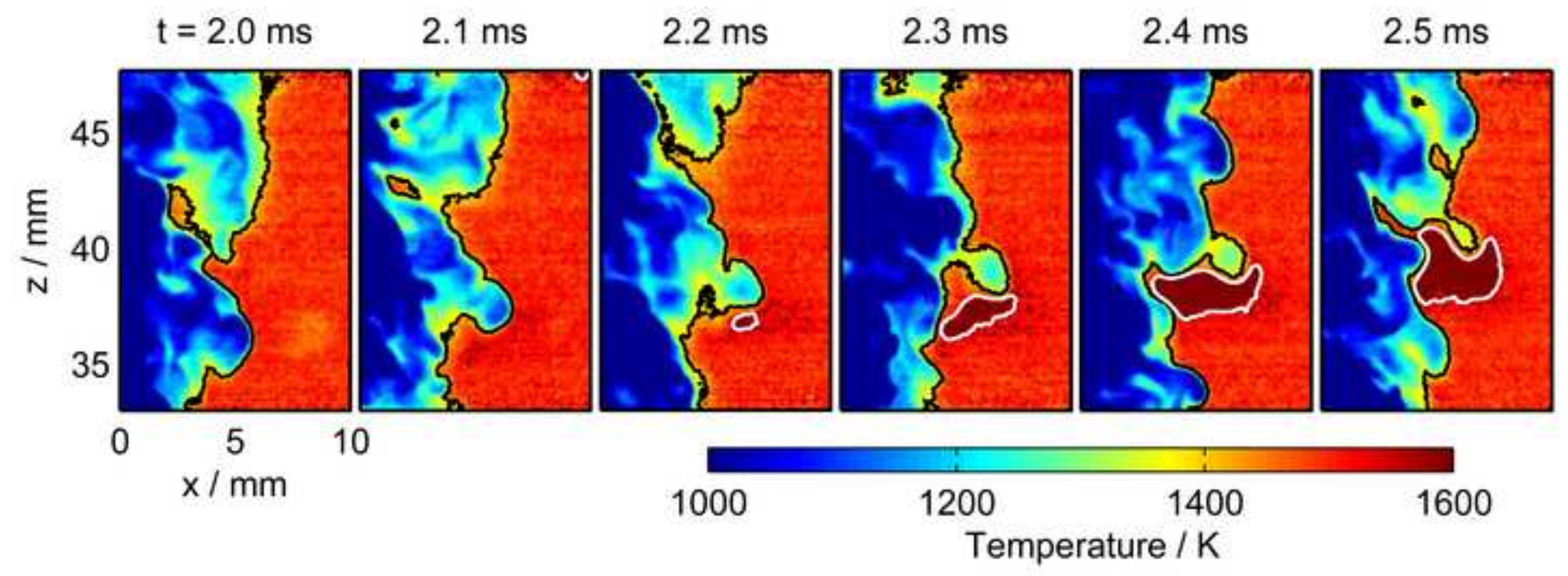


Figure 13

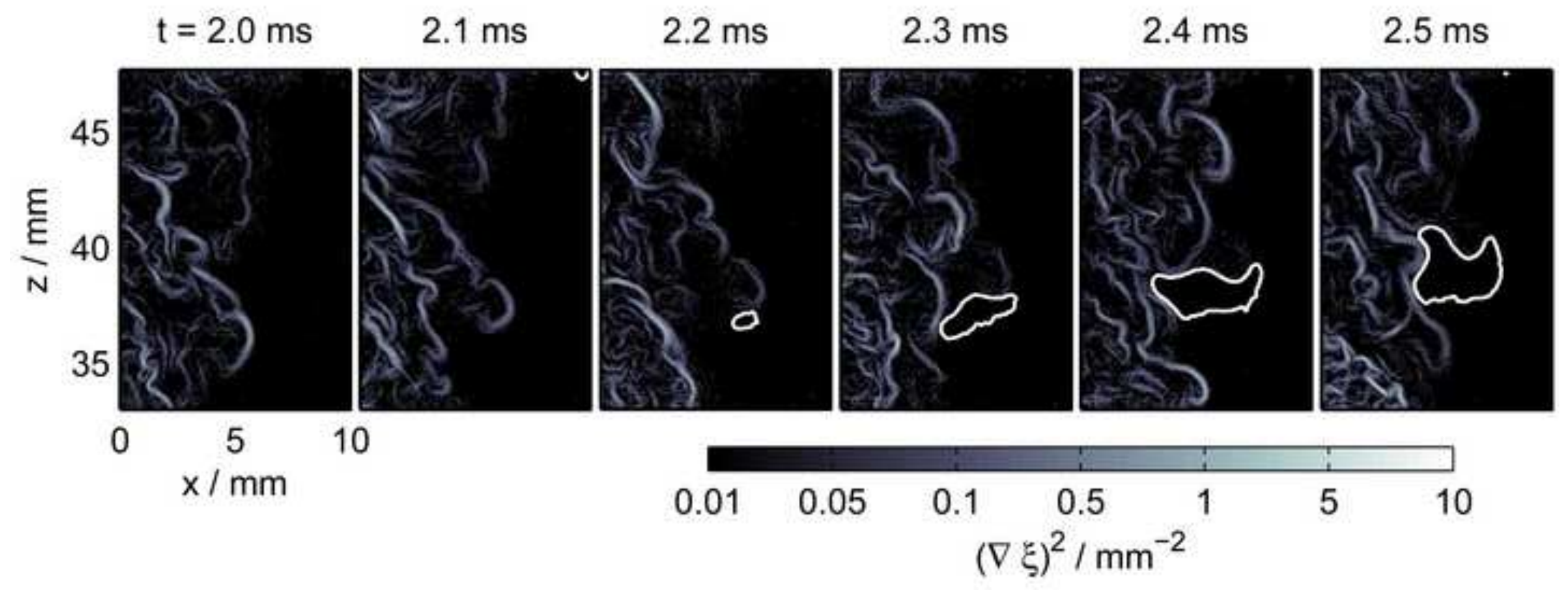


Figure 14

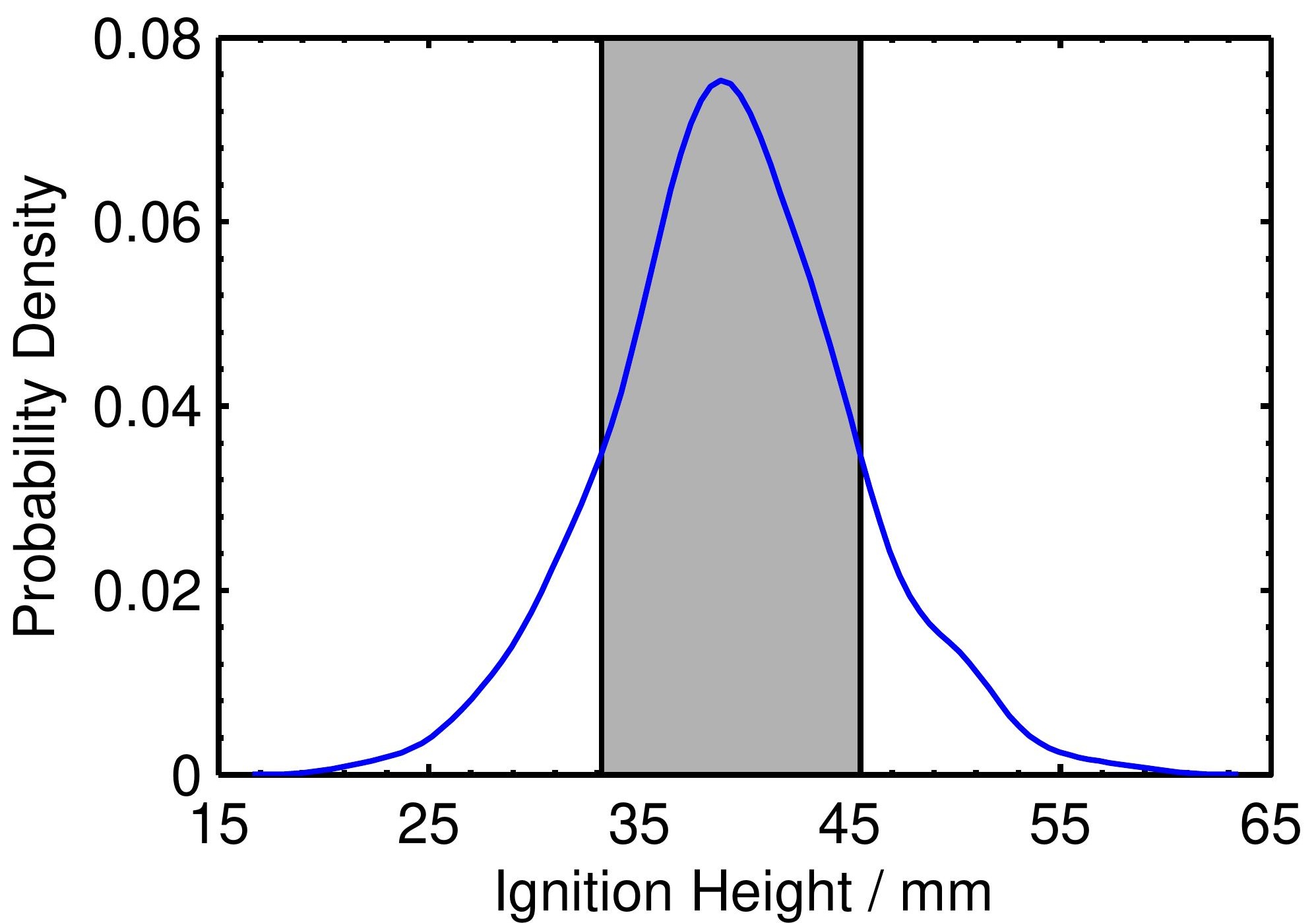


Figure 15

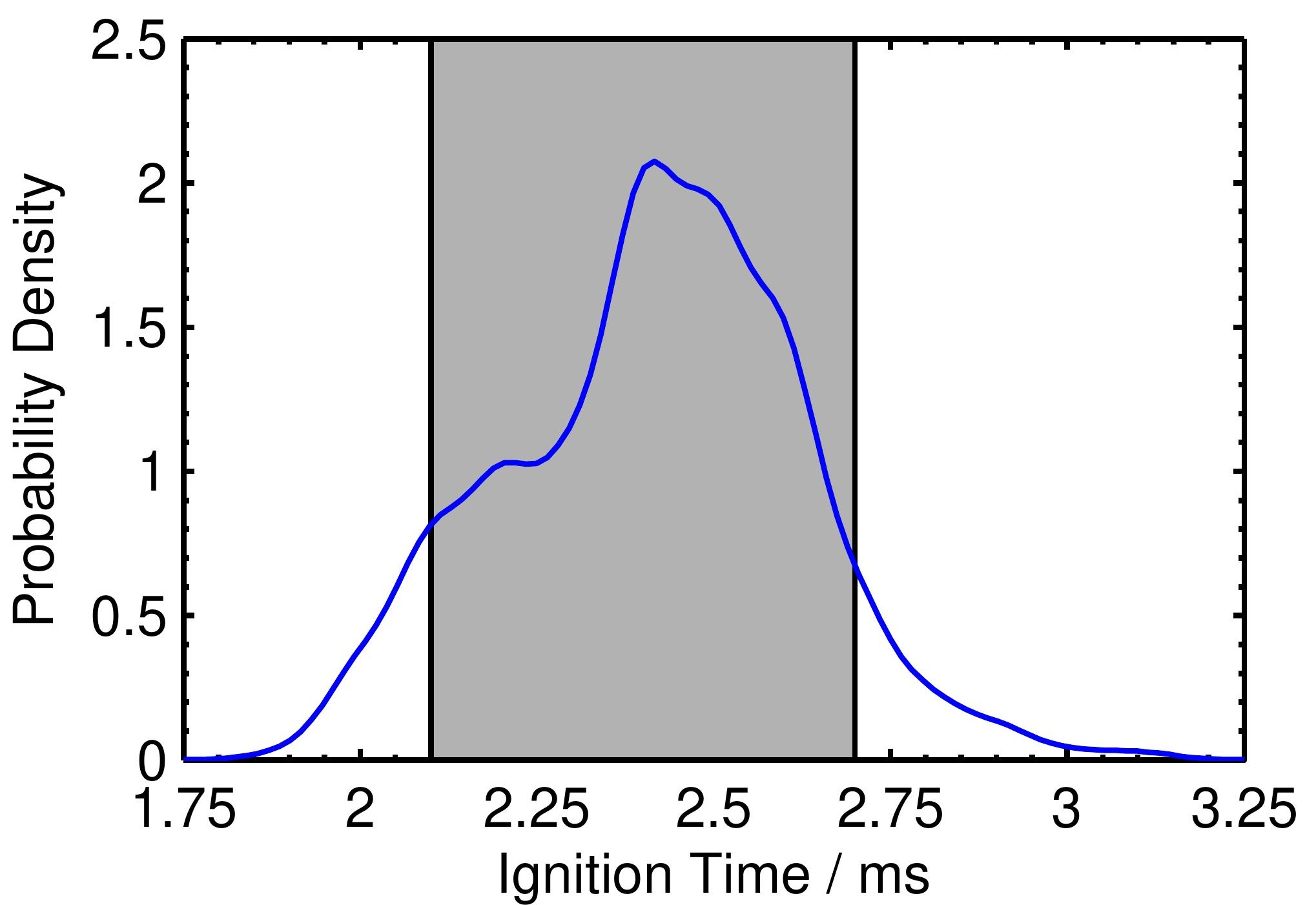


Figure 16

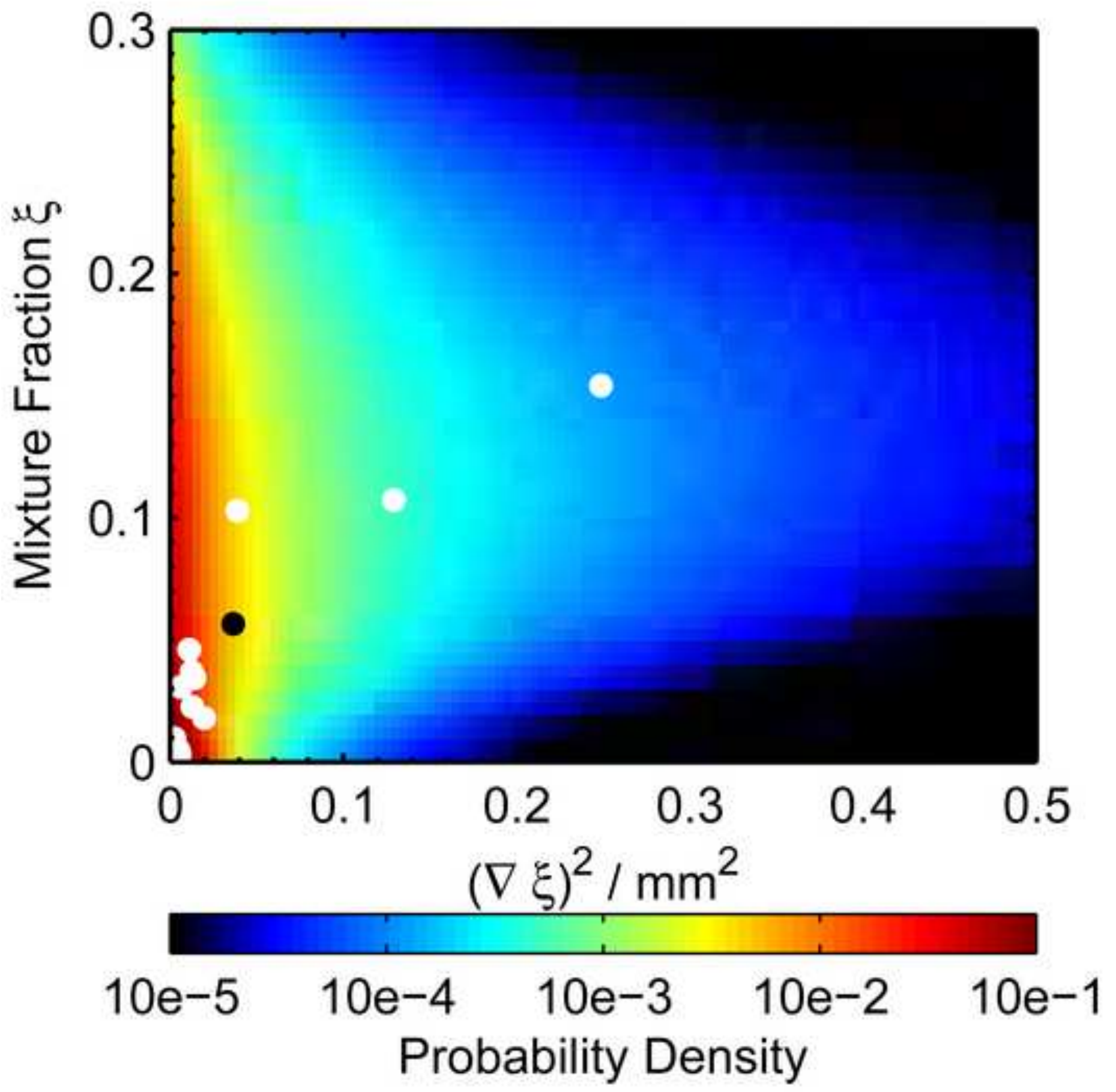

